\title{
Bioactivity Evaluation of a Novel Formulated Curcumin
}

\author{
Se-Chun Liao ${ }^{1}$, Wei-Hsiang Hsu ${ }^{2}{ }^{\mathbb{D}}$, Zi-Yi Huang ${ }^{2}$, Kun-Lin Chuang ${ }^{2}$, Kuan-Ting Lin ${ }^{3}$, \\ Chia-Ling Tseng ${ }^{4}$, Tung-Hu Tsai ${ }^{5} \odot$, Anh-Hoang Dao ${ }^{6}$, Chun-Li Su ${ }^{4,7, *}$ and \\ Chi-Ying F. Huang 1,2,8,*(D) \\ 1 Institute of Clinical Medicine, National Yang-Ming University, Taipei 112, Taiwan; \\ susanliao@everestpharm.com \\ 2 Institute of Biopharmaceutical Sciences, National Yang-Ming University, Taipei 112, Taiwan; \\ rabbitjim5@hotmail.com (W.-H.H.); laduree120@ym.edu.tw (Z.-Y.H.); jason101024004@gmail.com (K.-L.C.) \\ 3 Cold Spring Harbor Laboratory, Cold Spring Harbor, NY 11724, USA; woodydon777@gmail.com \\ 4 Department of Human Development and Family Studies, National Taiwan Normal University, Taipei 106, \\ Taiwan; piiq2005@hotmail.com \\ 5 Institute of Traditional Medicine, School of Medicine, National Yang-Ming University, Taipei 112, Taiwan; \\ thtsai@ym.edu.tw \\ 6 Department of Formulation and Processing, National Institute of Medicinal Materials, Hanoi 100000, \\ Vietnam; bccb@nimm.org.vn \\ 7 Graduate Program of Nutrition Science, School of Life Science, National Taiwan Normal University, \\ Taipei 106, Taiwan \\ 8 Department of Biochemistry, College of Medicine, Kaohsiung Medical University, Kaohsiung 807, Taiwan \\ * Correspondence: chunlisu@ntnu.edu.tw (C.-L.S.); cyhuang5@ym.edu.tw (C.-Y.F.H.); \\ Tel.: +886-277341436 (C.-L.S.); +886-228267904 (C.-Y.F.H.); \\ Fax: +886-223639635 (C.-L.S.); +886-228224045 (C.-Y.F.H.)
}

Received: 9 October 2019; Accepted: 19 November 2019; Published: 6 December 2019

\begin{abstract}
Curcumin has been used as a traditional medicine and/or functional food in several cultures because of its health benefits including anticancer properties. However, poor oral bioavailability of curcumin has limited its oral usage as a food supplement and medical food. Here we formulated curcumin pellets using a solid dispersion technique. The pellets had the advantages of reduced particle size, improved water solubility, and particle porosity. This pellet form led to an improvement in curcumin's oral bioavailability. Additionally, we used the C-Map and Library of Integrated Network-Based Cellular Signatures (LINCS) Unified Environment (CLUE) gene expression database to determine the potential biological functions of formulated curcumin. The results indicated that, similar to conventional curcumin, the formulated curcumin acted as an NF- $\kappa B$ pathway inhibitor. Moreover, ConsensusPathDB database analysis was used to predict possible targets and it revealed that both forms of curcumin exhibit similar biological functions, including apoptosis. Biochemical characterization revealed that both the forms indeed induced apoptosis of hepatocellular carcinoma (HCC) cell lines. We concluded that the formulated curcumin increases the oral bioavailability in animals, and, as expected, retains characteristics similar to conventional curcumin at the cellular level. Our screening platform using big data not only confirms that both the forms of curcumin have similar mechanisms but also predicts the novel mechanism of the formulated curcumin.
\end{abstract}

Keywords: curcumin; formulated curcumin; pharmacokinetics; aurora kinase A; hepatocellular carcinoma 


\section{Introduction}

The use of nutraceutical or functional and medical foods as alternative medicine, in addition to supplementary foods, has been on the rise in recent years [1,2]. The delivery of active ingredients is important in order to obtain beneficial effects for the human body.

Curcumin has been used for many years as a naturally occurring alternative medicine and functional food for the treatment of many diseases. Curcumin is a polyphenol extracted from the rhizome of Curcuma longa L., which has phenolic groups and conjugated double bonds [3]. It has strong anti-oxidant, anti-inflammatory, anti-septic, anti-proliferative, and wound-healing properties [4-8]. In addition, curcumin can reverse multidrug resistance of cancer cells, suggesting that it can also serve as a supplement to traditional chemotherapy [9,10]. Several lines of evidence show that curcumin exerts potent anticancer effects against a broad range of human cancer cells, including prostate, colon, breast, ovarian, lung, and liver cancers, and can induce cancer cell apoptosis, for example, in liver cancer cell lines, including but not limited to HepG2, SK-Hep-1, Hep3B, SUN449, and Huh7 cells, with low cytotoxic effects on normal cells [11-16].

Despite curcumin's beneficial effects, its low oral bioavailability (due to its low absorption in the gut because of low solubility in water, fast metabolism by the liver, and rapid systemic elimination) has limited its applications [17-19]. Various methods have been developed to improve the oral bioavailability of curcumin, such as the use of a natural enhancer, a curcumin-phospholipid complex, cyclodextrin and microemulsions, and the development of curcumin analogs [20-22]. In this study, we selected the pellet form, a multiple-unit dosage form, as a vehicle for compound delivery. Pellets disperse freely in the gastrointestinal tract, so they invariably maximize drug absorption [23]. In addition, to improve the solubility of curcumin, we used a solid dispersion technique to formulate pellets. In solid dispersions, the particle size of poorly soluble drugs is reduced and their wettability and dispersibility enhanced, thereby improving their dissolution and absorption rate [24].

The Connectivity Map (C-Map) is a systematic database that establishes the relationship between diseases, genes, and compounds [25]. Recently, the database has been expanded and renamed C-Map and Library of Integrated Network-Based Cellular Signatures (LINCS) Unified Environment (CLUE) (https://clue.io/) [26]. Briefly, C-Map and CLUE use gene expression profiles to describe the biological states of cultured human cancer or normal cells to determine their chemical or genetic constructs (short hairpin RNA [shRNA] constructs). The new, low-cost, high-throughput generic solution for gene expression profiles is termed "L1000." CLUE not only expands the 1309 compounds listed in C-Map to 19,811 small molecules but also includes 5075 shRNA and overexpression genes. In addition, users find CLUE relatively convenient to quickly search for a drug class with a similar mechanism of action (MOA) as a target drug or the same gene family of genetic perturbagens, they codify the class-level annotation required considerable effort, perturbagen classes (PCLs). For example, users can compare their target, such as a disease gene signature or a novel compound, with C-Map and CLUE through pattern-matching algorithms and predict dissimilarities (search for a drug to reverse a disease) or similarities (search for a similar MOA via known compounds). They could upload gene expression profiles to C-Map and CLUE to calculate the connectivity score of each profile. A positive connectivity score would indicate a degree of similar mechanism, while a negative connectivity score would denote the reverse.

HCC is the fifth-most common malignancy worldwide. More than $75 \%$ of HCC cases occur in the Asia-Pacific region. The high mortality rate because of HCC is due to the difficulty in diagnosis and poor prognosis. Chemotherapy is a traditional choice for inoperable HCC, but drug resistance limits the therapeutic effect $[27,28]$. Sorafenib is a multi-kinase inhibitor that targets Raf kinases as well as vascular endothelial growth factor receptor (VEGFR)-2/VEGFR-3, platelet-derived growth factor receptor beta (PDGFR- $\beta$ ), Flt-3, and c-Kit. Because of its potential in providing a survival advantage of two to three months, as per results of two-phase III clinical studies, sorafenib is a Food and Drug Administration (FDA)-approved, first-line targeted therapy agent for treating advanced HCC patients $[29,30]$. However, the low tumor response rate and side effects of sorafenib indicate the 
need for investigating other new potential drugs or supplementary foods for HCC [31,32]. In this study, we investigated the anticancer activity of conventional and formulated curcumin and their combination with sorafenib in order to determine whether this combination can induce HCC cell apoptosis and autophagy and inhibit HCC cell proliferation. Formulated curcumin can be used as a functional food and alternative medicine in cancer therapy as it not only causes mitotic defects and cell cycle arrest in cancer cells but also alters chemosensitivity toward anticancer drugs by inducing Aurora-A suppression.

\section{Materials and Methods}

\subsection{Materials and Methods Used in Manufacturing Formulated Curcumin}

\subsubsection{Preparation of Curcumin Solid Dispersion Loaded Pellet}

A curcumin standard with a purity $>95.6 \%$ was purchased from Sigma-Aldrich.

We used a solid dispersion technique to enhance the solubility and dissolution rate of curcumin [24]. Briefly, the process of making formulated curcumin included dispersing curcumin powder into a solid dispersion solution and spraying it onto sugar spheres. Tumeric extract powder contained 95\% curcumin in $80 \mathrm{~g}$ (as the active drug). The excipients used in the preparation process of solid dispersion curcumin were Polyvinylpyrrolidone \#k30 $800 \mathrm{~g}$ (PVP K30, as the non-volatile polymer solvent for curcumin) and alcohol $3200 \mathrm{~g}$ (as the volatile solvent for curcumin). The turmeric extract powder was mixed with the excipients. The drug-polymer interaction evenly dispersed curcumin in the solvent. Next, the solvent containing solid dispersion curcumin was loaded onto sugar spheres by spray-drying to make solid dispersion pellets; the solvent evaporated during fluid-bed granulation (Figure 1).

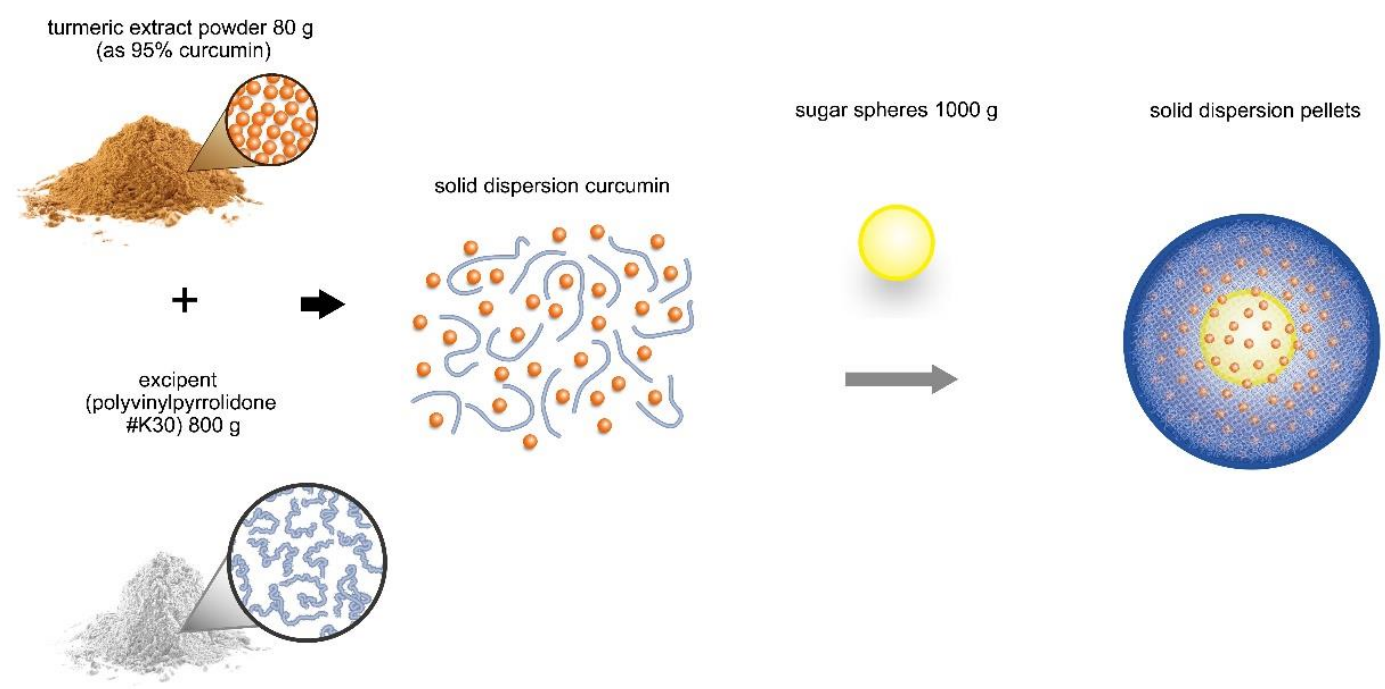

Figure 1. Preparation of solid dispersion curcumin. Turmeric extract powder, containing $80 \mathrm{~g}$ of 95\% curcumin (as the active drug), was mixed with excipients (800 $\mathrm{g}$ PVP as the nonvolatile polymer solvent in the presence of alcohol as the volatile solvent for curcumin). The drug-polymer interaction evenly dispersed curcumin in the solvent. Then, the solvent containing solid dispersion curcumin was loaded onto sugar spheres by fluid-bed granulation to make solid dispersion curcumin pellets. PVP, polyvinylpyrrolidone.

\subsubsection{Measurements of Particle Size and Zeta Potential}

Particle size (Z-average, $\mathrm{nm}$ ), polydispersity index (PDI), and $\zeta$-potential (ZP, mV) of curcumin particles after re-dispersion in water were determined at $25^{\circ} \mathrm{C}$ by dynamic light scattering (DLS) using a Zetasizer Nano ZS90 (Malvern Instruments, Malvern, UK). Measurements were performed with a detector at a fixed angle of $90^{\circ}$, in triplicate, and results were shown as mean $\pm \mathrm{SD}$. About $60 \mathrm{mg}$ 
of pellets were dispersed into $2 \mathrm{~mL}$ water and centrifuged at $2000 \times \mathrm{g}$ for 1 minute to remove starch particles originated from sugar spheres. Supernatant was aspirated to measure size and ZP.

\subsubsection{Dissolution Test}

A dissolution test was conducted by the US Pharmacopeia 41 basket method (apparatus 1) using a dissolution tester (708-DS Dissolution apparatus, Agilent, USA). The samples of $89 \mathrm{mg}$ conventional curcumin (equivalent to $72 \mathrm{mg}$ curcumin) and $2180 \mathrm{mg}$ formulated curcumin (equivalent to $72 \mathrm{mg}$ curcumin) were placed into $900 \mathrm{~mL}$ of dissolution medium containing $1 \%$ sodium dodecyl sulfate (SDS) at $37^{\circ} \mathrm{C} \pm 0.5^{\circ} \mathrm{C}$, under a stirring speed of $100 \pm 2 \mathrm{rpm}$. A $5 \mathrm{~mL}$ sample was withdrawn at each time interval $(5,10,15,20,30,45$, and 60 minutes) and was mixed and filtered through a $0.45-\mu \mathrm{m}$ pore membrane. Then, $2 \mathrm{~mL}$ of filtrate was diluted with mobile phase so that the total volume became $10 \mathrm{~mL}$ and subjected to HPLC analysis (Agilent 1260, USA). The HPLC program consisted of a mobile phase of tetrahydrofuran: $0.1 \%$ citric acid solution (4:6). The column used was $4.6 \mathrm{~mm} \times 20 \mathrm{~cm}$ with $5-\mu \mathrm{m}$ packing L1. The flow rate was $1 \mathrm{~mL} /$ minute, and the injection volume was $20 \mu \mathrm{L}$ using a $420 \mathrm{~nm}$ wavelength detector. The percentages of curcumin dissolved from the conventional curcumin and pellets (formulated curcumin) into the medium were calculated and compared.

\subsection{Pharmacokinetic Study}

\subsubsection{Animal Model}

All animal treatment procedures followed the Guide for the Care and Use of Laboratory Animals (National Institutes of Health (NIH) publication, 85-23, revised 1996) as well as the Animal research: Reporting in vivo experiments (ARRIVE) guidelines, and were approved by the Animal Research Committee at National Yang-Ming University, Taipei, Taiwan, under Institutional Animal Care and Use Committees (IACUC) approval no: 990103. All surgeries and experimental procedure were carried out under anesthesia with all efforts to minimize animal suffering.

Twelve male Sprague Dawley (SD) rats (270 \pm 15 g body weight) were obtained from Bio-Lasco, Taipei, Taiwan. Water was provided ad libitum, regardless of administration route. All animals were acclimatized and quarantined in quarantine room of the Rosetta animal facility for about 1 week, and then transferred to feeding room. The humidity and temperature were well controlled as $30 \%-70 \%$ and $19-25^{\circ} \mathrm{C}$. The light and dark cycle was set as $12 \mathrm{~h}: 12 \mathrm{~h}$. Food and drinking water were allowed $\mathrm{ad}$ libitum during housing.

Rats were randomly divided into two groups treated with curcumin and formulated curcumin. Curcumin (conventional; $500 \mathrm{mg} / \mathrm{kg}, n=6$ ) and $500 \mathrm{mg} / \mathrm{kg}$ formulated curcumin (equal to curcumin $60 \mathrm{mg} / \mathrm{kg}, n=6$ ) were administrated by gavage to the freely moving rats, respectively. A $300 \mu \mathrm{L}$ blood sample was collected from the tail vein into a tube rinsed with heparin at $0,0.25,0.5,1,1.5,2,4,6 \mathrm{~h}$ after oral administration.

\subsubsection{Sample Pretreatment}

Plasma was obtained by centrifuging the blood sample at $4000 \mathrm{rpm}$ for 10 minutes at $4{ }^{\circ} \mathrm{C}$. The $10 \mu \mathrm{L}$ plasma was mixed with $50 \mu \mathrm{L}$ of the internal standard solution containing $0.1 \mathrm{ng} / \mu \mathrm{L}$ of agomelatine. The samples were vortexed and centrifuged at 13,000 rpm for 5 minutes. The $50 \mu \mathrm{L}$ of supernatant was transferred to the $1.5 \mathrm{~mL}$ tube contained $50 \mu \mathrm{L}$ solution of $25 \%$ acetonitrile and $0.1 \%$ acetic acid. After that, $50 \mu \mathrm{L}$ of the solution was injected onto LC-MS system.

\subsubsection{LC/MS/MS Conditions and Data Analysis}

Curcumin concentrations in the samples were determined by positive ion electrospray tandem mass spectrometry using multiple reaction monitoring (MRM). Separation of curcumin was conducted on a Cosmosil column (5C18-MS-IIPacked column, $120 \AA$, $5 \mu \mathrm{m}, 4.6$ mm I.D. x 150 mm; NACALAI TESQUE, Inc., Japan) with a mobile phase of acetonitrile-water-formic acid. MS/MS conditions 
consisted of a declustering potential of $50 \mathrm{~V}$, desolvation temperature of $550{ }^{\circ} \mathrm{C}$, spray needle of $5500 \mathrm{~V}$, and collision energy of $30 \mathrm{~V}$.

Pharmacokinetic analysis was calculated using a non-compartmental model with the Phoenix

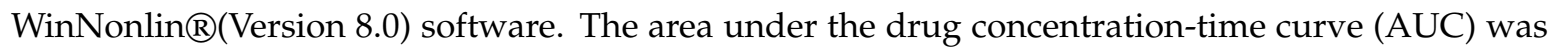
used to measure the total amount of curcumin reaching the systemic circulation. The relative oral bioavailability (BA) of curcumin was calculated according to the following equation: $\mathrm{BA}(\%)=100$ $\times\left[\left(\mathrm{AUC}_{\text {formulated curcumin }} /\right.\right.$ dose $\left._{\text {formulated curcumin }}\right] /\left[\left(\mathrm{AUC}_{\text {curcumin }} /\right.\right.$ dose $\left.\left._{\text {curcumin }}\right)\right]$. The pharmacokinetic results were represented as the mean \pm SD. Statistical analysis was performed by $t$ test (SPSS version 10.0) to compare the differences between groups. The level of significance was set at $p<0.05$.

\subsection{Cell Lines and Cell Culture}

The Huh7 and PLC5 cell lines were obtained from National Taiwan University Hospital, Taiwan. The Mahlavu cell lines were provided by Dr. Muh-Hwa Yang (Institute of Clinical Medicine, National Yang-Ming University, Taiwan). Hep3B cells were obtained from American Type Culture Collection (ATCC), Rockville, MD, USA.

HCC cell lines were cultured in Dulbecco's modified Eagle's medium (DMEM, GIBCO) supplemented with $10 \%(v / v)$ fetal bovine serum (FBS, GIBCO), non-essential amino acids (NEAA, GIBCO), L-glutamine (GlutaMAX ${ }^{\mathrm{TM}}-\mathrm{I}$ Supplement, GIBCO) and 10\% penicillin-streptomycin (GIBCO). These cells were maintained in a humidified incubator with $5 \% \mathrm{CO}_{2}$ at $37^{\circ} \mathrm{C}$ and were regularly subcultured every $2-3$ days.

\subsection{Drug Preparation and Cell Exposure}

The conventional curcumin was prepared as a $30 \mathrm{mM}$ stock solution in dimethyl sulfoxide (DMSO; Sigma) and stored at $-20^{\circ} \mathrm{C}$. Final curcumin concentrations of $1-90 \mu \mathrm{M}$ were obtained by dilution in culture medium so that the final concentration of DMSO was less than $1 \%$. Controls contained $0.1 \%$ DMSO in all experiments.

The formulated curcumin was prepared as a $30 \mathrm{mM}$ stock solution (based on the weight of curcumin) in double distilled water and stored at $-20{ }^{\circ} \mathrm{C}$. The formulated curcumin was diluted with cell culture medium to obtain the concentration indicated.

\subsection{Proliferation and Viability Assays}

Cells were seeded into a 96-well plate (1500-2000 cells/well) overnight and then treated with curcumin and the formulated curcumin respectively for $0,24,48,72,96$ and $120 \mathrm{~h}$. After treatment, $0.5 \mu \mathrm{g} / \mathrm{mL}$ 3-(4,5-cimethylthiazol-2-yl)-2,5-diphenyl tetrazolium bromide (MTT) was added to each well and cultured for $2 \mathrm{~h}$ at $37^{\circ} \mathrm{C}$. After incubation, the media were removed from the wells. The formazan crystals formed were then solubilized in DMSO at room temperature for 10 minutes, and then the absorbance was measured in a multimode microplate reader at $570 \mathrm{~nm}$.

\subsection{Mitochondrial Membrane Potential Assay}

We employed 5, 5', 6, 6'-tetrachloro-1, 1', 3, 3'-tetraethylbenzimidazolcarbocyanine iodide (JC-1), which was obtained from Cayman Chemical Co., to analyze the mitochondrial membrane potential. The cells were seeded in 96-well black plates at a density of 7000 cells/well and cultured overnight. After treatment, JC-1 staining solution was added to each well and incubated at $37^{\circ} \mathrm{C}$ for $15-30$ minutes in the dark. The plates were obtained by centrifuged at $400 \times g$ at room temperature for 5 minutes, and the supernatant was discarded. Then, JC-1 assay buffer was added to each well, followed by centrifugation at $400 \times g$ at room temperature for 5 minutes, after which the supernatant was discarded. Finally, JC-1 assay buffer was added again to each well for fluorescent analysis using a fluorescent plate reader. 


\subsection{Annexin V and Propidium Iodide (PI) Double Staining by Flow Cytometry}

The Huh7 were incubated with various concentrations of conventional and formulated curcumin for $24 \mathrm{~h}$. Annexin V/PI staining was performed to quantify cell apoptosis using an Annexin V-fluorescein isothiocyanate (FITC) Apoptosis Detection Kit (BioVision, Inc., Milpitas, CA, USA) according to the manufacturer's protocol. Annexin V-FITC was then added followed by incubation for 15 minutes in the dark in a $100 \mu \mathrm{L}$ cell suspension. PI was then spiked into $400 \mu \mathrm{L}$ Annexin V binding buffer and added immediately to the cell suspension, and subsequently analyzed on a FACScan flow cytometer (BD Biosciences, USA).

\subsection{Western Blot}

The cells were incubated with various treatment (conventional and formulated curcumin or combination of sorafenib and conventional and formulated curcumin), and then collected for western blot. Aliquots of cell lysates containing 20-50 $\mu \mathrm{g}$ of protein were separated by SDS-polyacrylamide gel electrophoresis (SDS-PAGE), transferred onto a polyvinylidene difluoride (PVDF) membrane and detected using specific primary and secondary antibodies. The protein bands were visualized by an enhanced chemiluminescence (ECL) detection kit (Immobilon ${ }^{\mathrm{TM}}$ western, Millipore). The membranes were reprobed for $\beta$-actin as a loading control. All western blots were carried out at least three times for each experiment. The data were normalized to $\beta$-actin. The following primary antibodies were used: anti-extracellular regulated protein kinases (ERK), anti-caspase-3, anti-poly (ADP-ribose) polymerase (PARP) (all from Cell Signaling Technology) and anti-aurora kinase A (AURKA) (BD Biosciences). All antibodies were used at a 1:1000 dilution.

\subsection{Cell Cycle Analysis}

After treatment, the cells were collected by trypsinization and fixed in precooled $70 \%$ ethanol overnight. The cells were then incubated with PI in the presence of RNase A. The DNA content was analyzed by a FACSCalibur, and the data were analyzed by Flowjo software. The percentage of cells in the sub-G1 was used to indicate the apoptosis rate.

\subsection{Analysis the Similar Mechanism of Gene Expression Profiles of Conventional and Formulated Curcumin} Using the L1000 Microarray

Human HCC (HepG2) and human colorectal cancer (HT29) cell lines (ATCC) were treated in triplicate with $20 \mu \mathrm{M}$ of conventional curcumin or $2 \mu \mathrm{M}$ of formulated curcumin. Briefly, for experiments using formulated curcumin, $2 \mu \mathrm{M}$ of curcumin formulation and curcumin excipient were dissolved in DMSO and incubated with HepG2 and HT29 cell lines. The samples were submitted to Genometry, Inc. (Cambridge, MA, USA) for L1000 microarray analysis and to obtain the gene expression profiles of formulated curcumin in HepG2 and HT29. Each set of gene expression profiles consisted of upand down-regulated gene signatures. Subsequently, CLUE was used to decipher the gene signatures in order to uncover potential mechanisms via mapping to compounds with known MOAs. To filter output data, we used a score $>90$ for compounds and a score $>70$ for PCLs.

\subsection{Statistical Analysis}

All values were expressed as the mean \pm SD. The data were analyzed using a two-tailed student's $t$ test. A $p<0.05$ was considered as statistically significant.

\section{Result}

\subsection{Preparation and Evaluation Formulated Curcumin}

First, we prepared the formulated curcumin from powder to pellets with a solid dispersion technique as described in detail in the Materials and Methods section. The pellet size of formulated 
curcumin estimated by sieving was distributed in the range of $830-1000 \mu \mathrm{m}$. Curcumin content quantified by HPLC was $3.3 \%$. Z-average $(\mathrm{nm})$, PDI, and ZP $(\mathrm{mV})$ of curcumin particles after re-dispersion in water were $141.9 \pm 5.1,0.308 \pm 0.029$ and $-2.49 \pm 0.39$, respectively (Table 1 ). The dissolution rates of conventional curcumin were $0.00 \%, 9.80 \%, 13.60 \%, 14.05 \%, 17.28 \%, 19.41 \%$, $24.06 \%$, and $26.28 \%$, while those of the formulated curcumin were $0.00 \%, 59.03 \%, 87.50 \%, 98.78 \%$, $100.22 \%, 101.20 \%, 102.29 \%$, and $103.65 \%$ at $0,5,10,15,20,30,45$, and 60 minutes, respectively (Supplementary Figure S1). In the $1 \%$ SDS medium, more than $85 \%$ of curcumin was almost immediately released from the pellets after 10 minutes. Additionally, when compared to the US Pharmacopeia specifications for dissolution of curcuminoid capsules or curcuminoid tablets, the dissolution of the formulated curcumin was not lower than $75 \%$ after 60 minutes, suggesting that the formulation greatly increased curcumin's solubility.

Table 1. Properties of formulated curcumin.

\begin{tabular}{cc}
\hline Properties of Formulated Curcumin & Value \\
\hline Pellet size $(\mu \mathrm{m})$ & $830-1000$ \\
Curcumin level $(\%)$ & 3.3 \\
Z-average $(\mathrm{nm})$ & $141.9 \pm 5.1$ \\
Polydispersity index $(\mathrm{PDI})$ & $0.308 \pm 0.029$ \\
Zeta potential $(\mathrm{mV})$ & $-2.49 \pm 0.39$ \\
\hline
\end{tabular}

\subsection{Oral Administration of Formulated Curcumin Shows an Increase in Bioavailability over Conventional Curcumin via Pharmacokinetic Analysis}

To determine the actual amount of curcumin that was released and existed in the formulated curcumin, a high-performance liquid chromatography assay and LC-MS method was adopted for the quantification of curcumin. To investigate whether the bioavailability of curcumin was increased after formulation, $60 \mathrm{mg} / \mathrm{kg}$ of formulated curcumin was orally administered in a rat model and the plasma samples were subjected to chromatography. To confirm the reliability of the method for analyzing curcumin in plasma samples, a method validation was performed. The retention times of curcumin were about 5.14 minutes, with no visible interference peak in the blank plasma chromatogram (data not shown). To perform a pharmacokinetic analysis, the curcumin concentrations in rat plasma at different time points following oral administration of $500 \mathrm{mg} / \mathrm{kg}$ of curcumin and $60 \mathrm{mg} / \mathrm{kg}$ of formulated curcumin were compared (Figure 2). However, administration of $500 \mathrm{mg} / \mathrm{kg}$ of curcumin had very low amount of curcumin in rat plasma and resulted to a huge increase of bioavailability. Therefore, the pharmacokinetic parameters of curcumin represented an estimated number and will be compared with others from literatures (see later in discussion). AUC represents the total drug exposure over time. Based on the pharmacokinetic parameters (Table 2), the AUC represents the total drug exposure over time. The AUC normalized by dose of curcumin was increased from 0.0021 to 1.864 , which is an 887.6-fold increase after formulation. Overall, this result showed that oral administration of formulated curcumin significantly increased the oral bioavailability of curcumin compared with conventional curcumin.

\subsection{Gene Expression Analysis of Formulated Curcumin and Prediction of Highly Correlated Pathways}

We queried CLUE with regard to the analyzed group of genes in order to identify potential biological functions of formulated curcumin. The top 30 compounds (Figure 3C) and PCLs (Figure 3A) with the highest scores were obtained from CLUE. Intersection of results from both cell lines revealed that seven compounds (e.g., menadione and angiogenesis inhibitor; Figure 3D) and two PCLs (e.g., NF-kB pathway inhibitors; Figure 3B) shared common functions with conventional curcumin. In summary, formulated curcumin was similar to conventional curcumin, and both functioned as, for example, NF- $\mathrm{kB}$ pathway inhibitors, which is consistent with previous studies [33]. We intersected two sample groups to identify common PCL/compound classes between formulated curcumin treatment of HT29 cells and 
formulated curcumin treatment of HepG2 cells. Consequently, we identified two PCLs (including NF-kB pathway inhibitors and vesicular transport loss of function (LOF; Figure 3B), and seven compounds belonging to the NF- $\mathrm{KB}$ pathway inhibitor PCL class were common among all groups.

In fact, CLUE revealed that only the MOA of compounds or shRNAs was similar to that of formulated curcumin; CLUE did not indicate the target of formulated curcumin. Therefore, to obtain more information about formulated curcumin, we used another database for assistance pathway analysis, ConsensusPathDB (CPDB). CPDB comprises interactions among different types of various intracellular information, such as genes, RNA, proteins, and metabolites, to predict a relatively comprehensive and unbiased cellular biology signal result. We used the Venny website to intersect our two sets of PCL results (Figure 3B) and selected their targets and members genes to predict potential pathways of formulated curcumin (Figure 4). According to $q<0.001$, we listed the top 20 pathways at the bottom of Figure 4, and the details are in Supplementary Figure S2. In addition, we showed similar effects in L1000 microarray profiles between conventional and formulated curcumin in heatmaps (Figure 5). These data suggested that formulated curcumin exhibits similar biological functions as conventional curcumin.

Table 2. Pharmacokinetic parameters of curcumin in rat plasma following oral administration.

\begin{tabular}{ccc}
\hline & \multicolumn{2}{c}{ Oral } \\
\cline { 2 - 3 } Parameters & $\mathbf{5 0 0 ~} \mathbf{~ g} / \mathbf{k g}$ & Formulated Curcumin $(\boldsymbol{n}=\mathbf{6})$ \\
\cline { 2 - 3 } & $0.704 \pm 0.272$ & $\mathbf{6 0 ~} \mathbf{~ g} / \mathbf{k g}$ \\
\hline $\mathrm{C}_{\max }(\mathrm{ng} / \mathrm{mL})$ & $1.1 \pm 1.2$ & $109.200 \pm 41.651$ \\
$\mathrm{AUC}_{0-\mathrm{t}}(\mathrm{h} \times \mathrm{ng} / \mathrm{mL})$ & $0.0022 \pm 0.0024$ & $111.8 \pm 16.4$ \\
$\mathrm{AUC}_{0-\mathrm{t}} / \mathrm{Dose}$ & $1.25 \pm 0.83$ & $1.863 \pm 0.273$ \\
$\mathrm{~T}_{\max }(\mathrm{h})$ & $0.38 \pm 0.14$ \\
\hline
\end{tabular}

The data are expressed as the mean $\pm S D$. $C_{\max }$ : the maximum plasma concentration; $\mathrm{T}_{\max }$ : the time at which $C_{m a x}$ is observed; $\mathrm{AUC}_{0-\mathrm{t}}$ : area under the concentration-time curve from the time of drug administration to the last quantifiable concentration. *: Conventional curcumin in some rat plasma samples was very low and was assigned to 0 for calculations. We were unable to detect curcumin from the plasma of one rat during the experimental periods, and thus data from five rats were used for calculations.

(A)

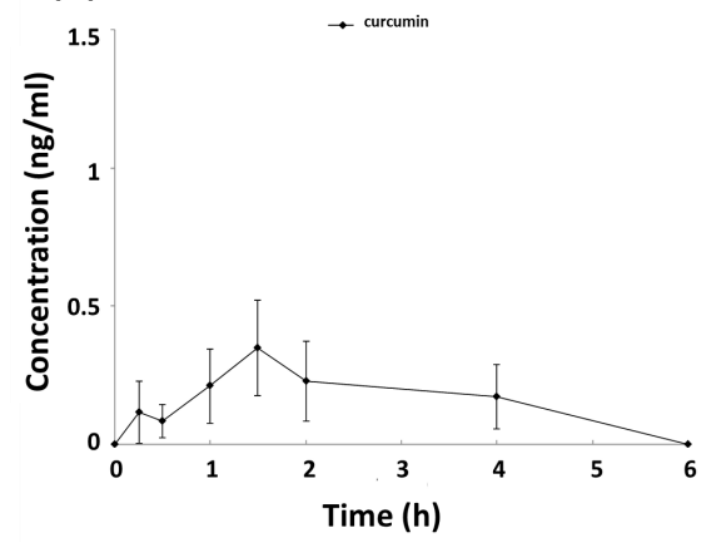

(B)

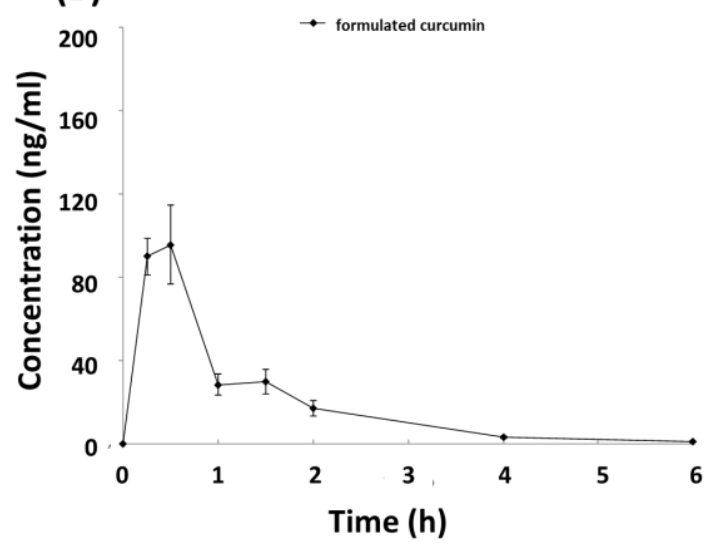

Figure 2. Mean plasma concentration-time profiles of curcumin in male SD rats following $500 \mathrm{mg} / \mathrm{kg}$ conventional curcumin (A) and $60 \mathrm{mg} / \mathrm{kg}$ formulated curcumin (B) after single dose oral gavage (P.O.) linear ordinate. The data are expressed as mean $\pm \mathrm{SD}, n=5$ for curcumin and $n=6$ for formulated curcumin. 
(A)

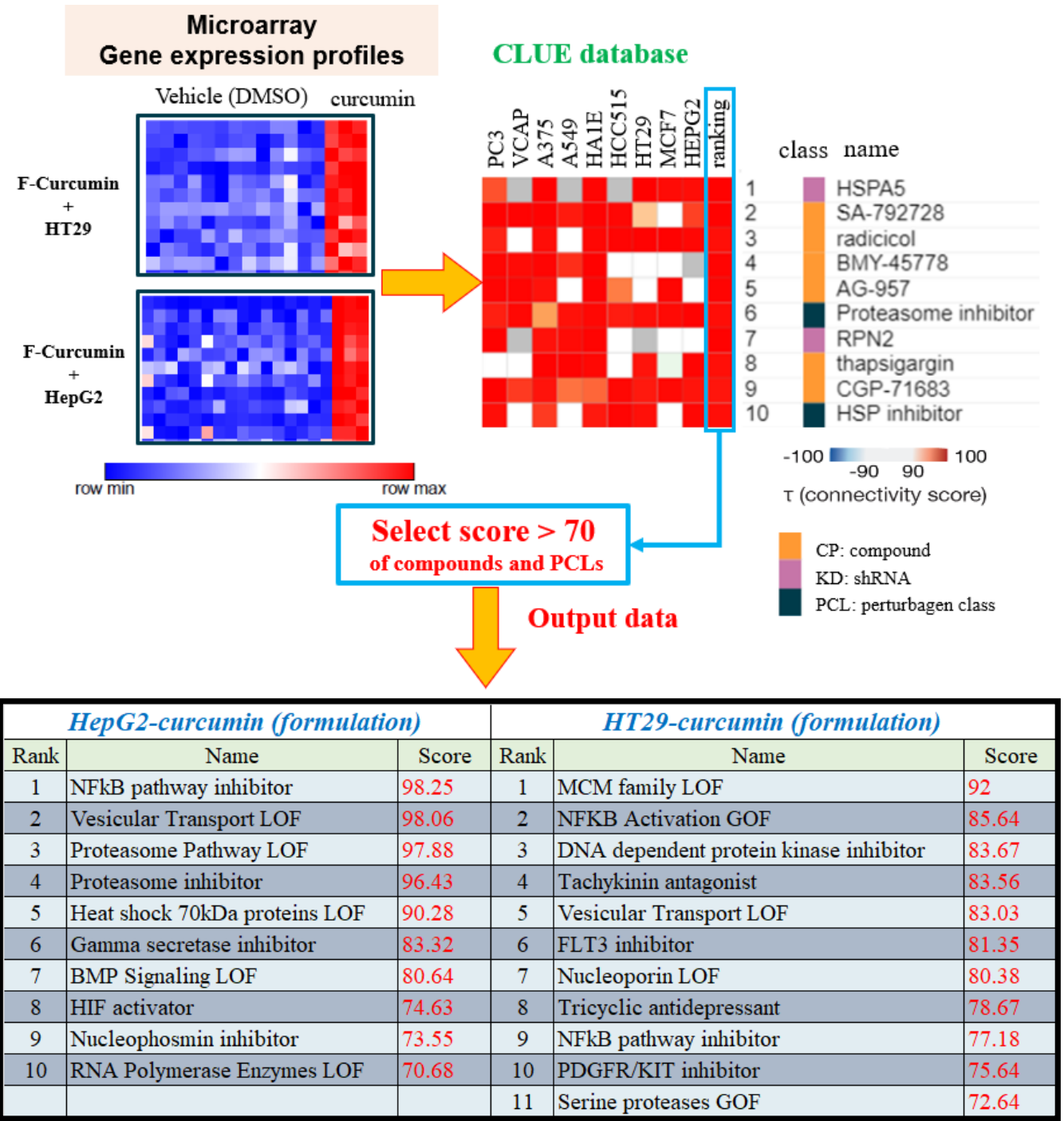

(B)

HepG2

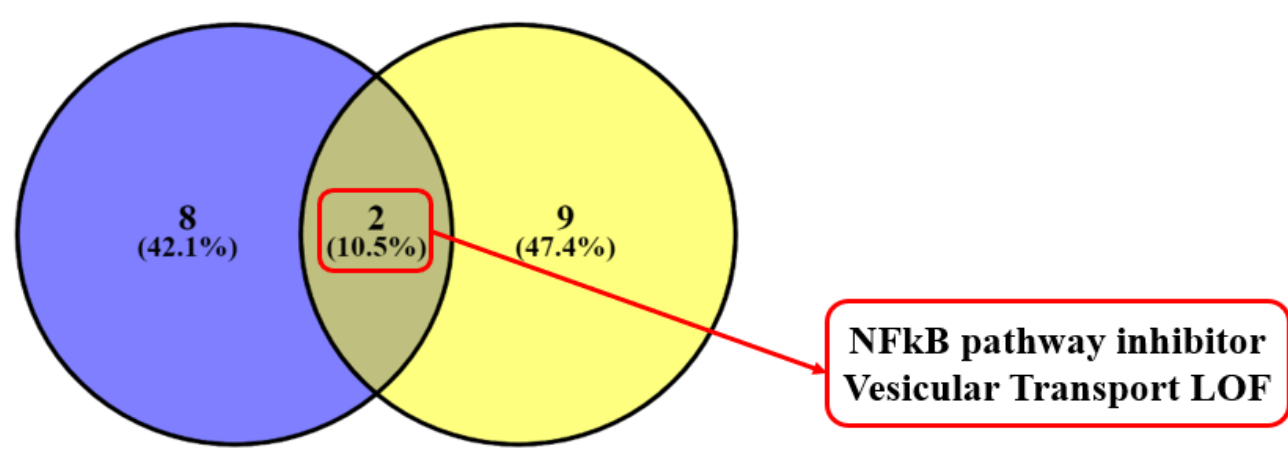

Figure 3. Cont. 
(C)

\begin{tabular}{|c|c|c|c|c|c|}
\hline \multicolumn{3}{|c|}{ HepG2 } & \multicolumn{3}{|c|}{ HT29 } \\
\hline rank & Drug name & score & rank & Drug name & score \\
\hline 1 & iodoacetic-acid & 99.4 & 1 & celastrol & 99.93 \\
\hline 2 & tretinoin & 98.84 & 2 & erythrosine & 99.93 \\
\hline 3 & Ala-Ala-Phe-CMK & 98.73 & 3 & R0-90-7501 & 99.72 \\
\hline 4 & WR-216174 & 98.7 & 4 & clopidogrel & 99.58 \\
\hline 5 & sappanone-a & 98.41 & 5 & W-7 & 99.34 \\
\hline 6 & caffeic-acid & 98.17 & 6 & PPT & 99.33 \\
\hline 7 & AG-957 & 97.77 & 7 & gatifloxacin & 99.26 \\
\hline 8 & capsazepine & 97.42 & 8 & carbidopa & 99.19 \\
\hline 9 & 4-hydroxy-2-nonenal & 97.4 & 9 & SU-11652 & 99.19 \\
\hline 10 & pifithrin-mu & 97.36 & 10 & dipropyl-dopamine & 99.08 \\
\hline 11 & tosyl-phenylalanyl-chloromethyl-ketone & 97.32 & 11 & n-formylmethionylalanine & 98.73 \\
\hline 12 & SA-792709 & 97.26 & 12 & metformin & 98.73 \\
\hline 13 & SSR-69071 & 97.22 & 13 & oxindole-I & 98.44 \\
\hline 14 & 15-delta-prostaglandin-j2 & 96.97 & 14 & dichloroacetic-acid & 98.34 \\
\hline 15 & BCL2-inhibitor & 96.95 & 15 & acyclovir & 98.14 \\
\hline 16 & quinidine & 96.88 & 16 & rifampicin & 98.13 \\
\hline 17 & isoliquiritigenin & 96.72 & 17 & thiothixene & 98.06 \\
\hline 18 & parthenolide & 96.69 & 18 & AKT-inhibitor-1-2 & 97.83 \\
\hline 19 & SA-792728 & 96.62 & 19 & methyl-angolensate & 97.46 \\
\hline 20 & NSC-3852 & 96.62 & 20 & LDN-193189 & 97.32 \\
\hline 21 & SCH-58261 & 96.59 & 21 & BRD-A81377415 & 97.29 \\
\hline 22 & LDN-193189 & 96.58 & 22 & auranofin & 97.29 \\
\hline 23 & menadione & 96.58 & 23 & cefoxitin & 97.25 \\
\hline 24 & rhamnetin & 96.52 & 24 & propranolol & 96.86 \\
\hline 25 & atracurium & 96.39 & 25 & methylene-blue & 96.85 \\
\hline 26 & flavokavain-b & 96.34 & 26 & rimcazole & 96.61 \\
\hline 27 & MDM2-inhibitor & 96.2 & 27 & doxazosin & 96.61 \\
\hline 28 & pyrrolidine-dithiocarbamate & 96.17 & 28 & temsirolimus & 96.41 \\
\hline 29 & sulforaphane & 96.02 & 29 & maprotiline & 96.33 \\
\hline 30 & tyrphostin-47 & 95.92 & 30 & tivozanib & 96.3 \\
\hline
\end{tabular}

(D)

HepG2

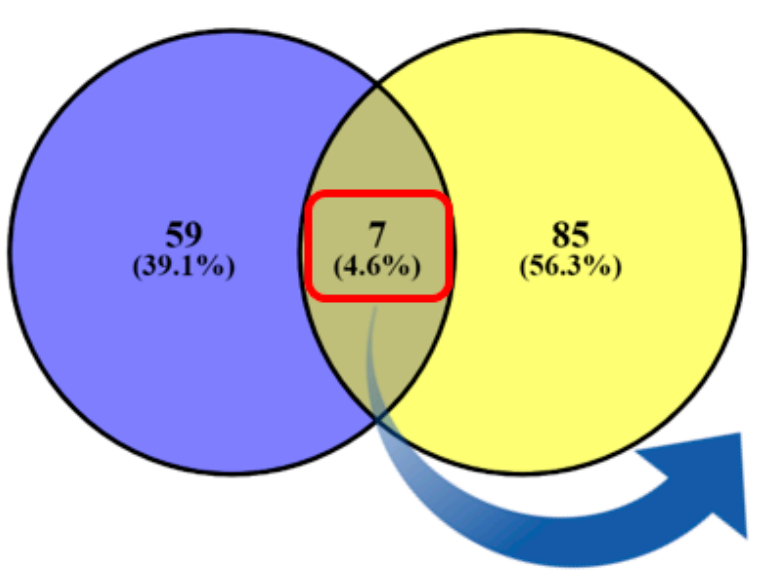

HT29

SCH-58261

LDN-193189

menadione

NSC-663284

dipropyl-dopamine angiogenesis-inhibitor RO-90-7501

Figure 3. Gene analysis data of formulated curcumin. (A) The L1000 gene expression profiles of HT29 and HepG2 cells treated with formulated curcumin were analyzed by CLUE. The output data of PCLs 
in both HT29 and HepG2 are shown at the bottom (score > 70). (B) PCLs list a score $>70$ and are intersected by Venny website. Two common PLCs, NF- $\mathrm{kB}$ pathway inhibitor and vesicular transport LOF, are shown in the diagram. To avoid missing possible predicted functions of formulated curcumin, we used an intersection-driven approach to broadly cover these PCLs (score > 70). (C) The top 30 compounds $(\mathrm{CP})$ are representative, while the complete list is provided in the Supplementary Information (score > 90). Details are in Supplementary Figure S3. (D) Intersection compounds using L1000 array analysis of formulated curcumin by CLUE. The connectivity score is based on the Kolmogorov-Smirnov enrichment statistical evaluation of each gene expression profile. The results provided from CLUE are expressed as a comprehensive connectivity score, showing that the same drug has a similar MOA on different cancer cells in CLUE, Connectivity Map and Library of Integrated Network-Based Cellular Signatures (LINCS) unified environment; PCL, perturbagen class; MOA, mechanism of action.

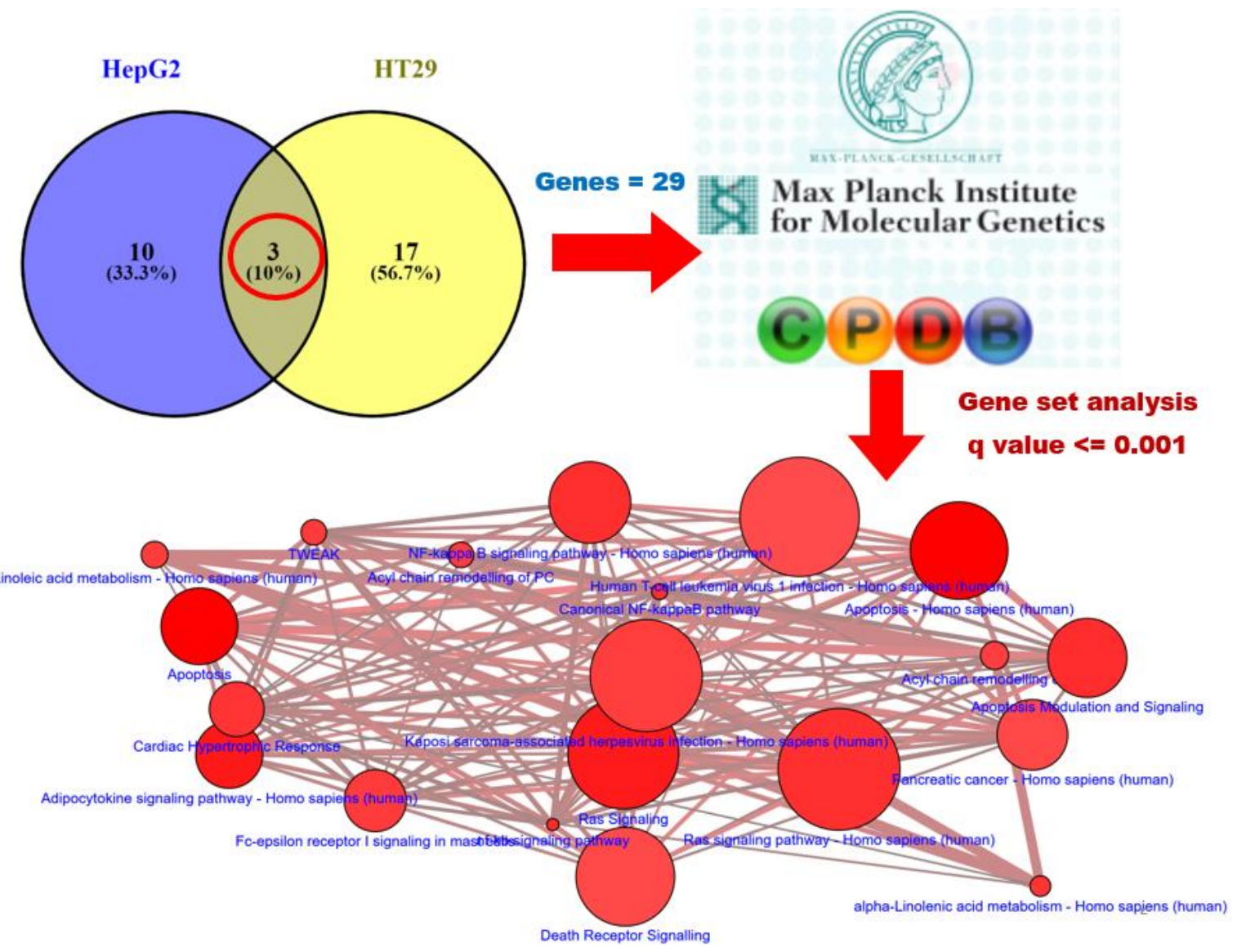

Figure 4. Possible pathways of formulated curcumin predicted by CPDB. Genes in two datasets were used to query $\mathrm{CPDB}$ in order to predict the pathways in which these genes were likely participating. The Venn diagram shows the intersecting PCLs (top, right). We focused on intersection results indicated by red circles. The results contained two PCLs, NF-kB pathway inhibitors and vesicular transport LOF and used their targets and member gene lists (total 22 genes) to query CPDB in order to analyze interaction network modules, biochemical pathways, and functional information. Top 50 prediction pathways are listed in Supplementary Figure S2, and top 20 pathways identified by CPDB analysis $(q<0.001)$ are shown at the bottom of the figure. The size of each dot denotes the entity number of genes in the pathway. The line between two dots was calculated by the function of these two pathways to indicate the number of genes overlapping said pathways. The breadth of the line denotes the strength of the correlation between two dots. The apoptosis was analyzed in this study (highlighted in yellow, Supplementary Figure S2). CPDB, ConsensusPathDB; PCL, perturbagen class; shRNA, short hairpin RNA. 


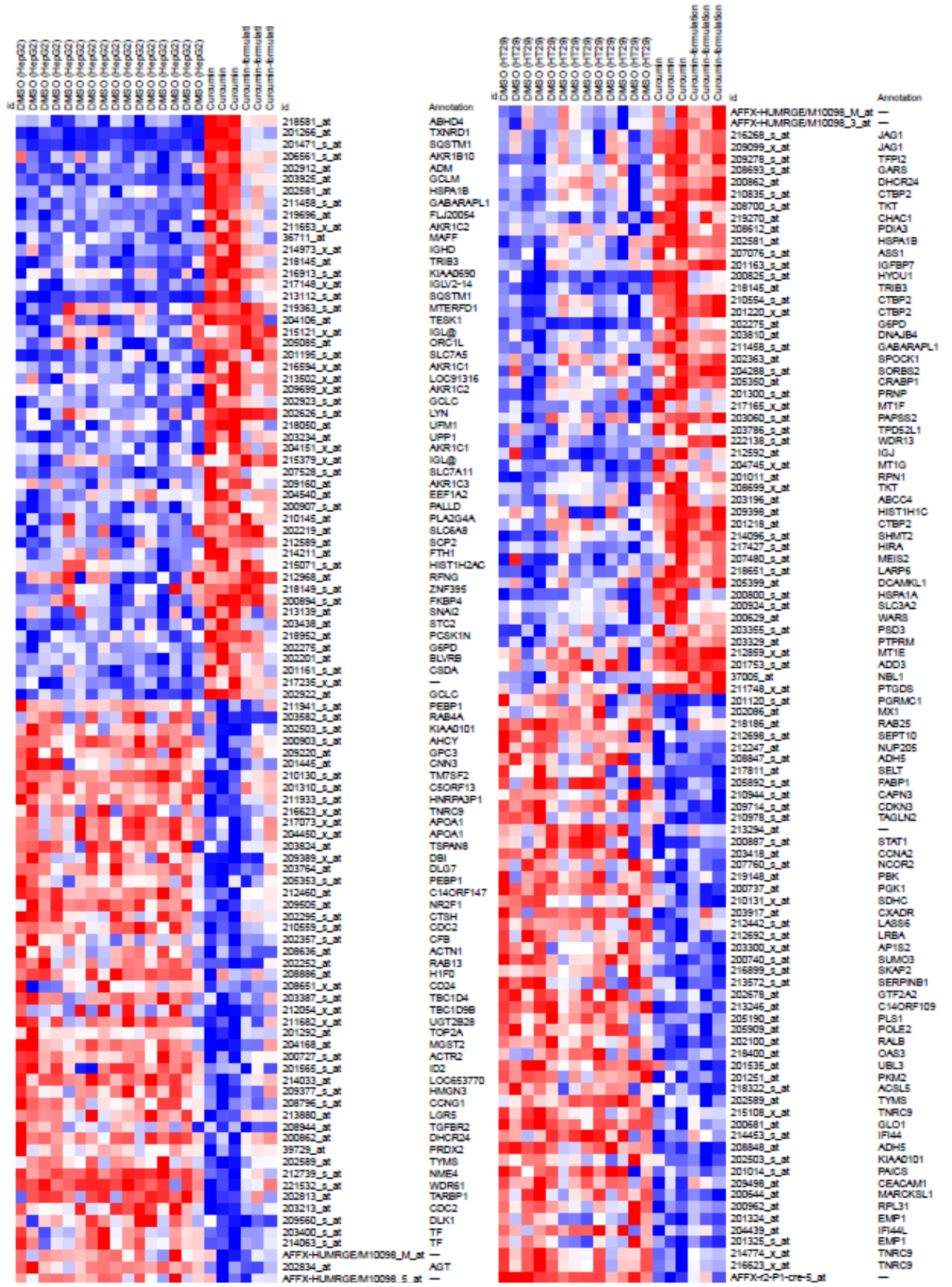

Figure 5. Heatmaps showing the top 50 up/down L1000 probes with similar expression patterns between conventional and formulated curcumin in HepG2 and HT29 cells, respectively. The horizontal axis denotes the treatments in three groups: (1) DMSO, (2) conventional curcumin, and (3) formulated curcumin. The vertical axis denotes the L1000 probe IDs and their corresponding gene names.

\subsection{Formulated Curcumin Displays Stronger Inhibition on Population Growth of Huh7 Cells}

To determine whether formulated curcumin retains the biological functions of conventional curcumin, we performed MTT assay to assess the cell proliferation and cell viability of conventional curcumin and formulated curcumin-treated Huh7 cells. As shown in Supplementary Figure S4, when the concentration of conventional or formulated curcumin increased, cell viability decreased after treatment with curcumin for 24-120 h. We also observed cytotoxicity of curcumin in Huh7 cells. The $50 \%$ inhibitory concentration $\left(\mathrm{IC}_{50}\right)$ value for conventional curcumin at $24,48,72,96$, and $120 \mathrm{~h}$ 
was around $90,90,60,45$, and $30 \mu \mathrm{M}$, respectively, while the $\mathrm{IC}_{50}$ value for formulated curcumin was around $60,60,30,10$, and $10 \mu \mathrm{M}$, respectively.

\subsection{Cytotoxic Effect of Curcumin on Other HCC Cell Lines}

To determine whether conventional and formulated curcumin could mediate the survival of other HCC cell lines, we first examined the effect of conventional and formulated curcumin on the viability of Huh7, Mahlavu, and PLC5 cells using MTT assay. While Huh7 cells are well differentiated, Mahlavu and PLC5 cells are poorly differentiated and carry p53 mutations. To explore the cytotoxic activity of conventional and formulated curcumin against these HCC cell lines, we initiated an in vitro study by treating Huh7, Mahlavu, and PLC5 cells each with increasing dosages of conventional and formulated curcumin $(0,1,3,10,30,60$, and $90 \mu \mathrm{M})$ for $72 \mathrm{~h}$. MTT assay results indicated that both conventional and formulated curcumin significantly inhibit the viability of Huh7 (Figure 6A), Mahlavu (Figure 6B), and PLC5 (Figure 6C) cells. After $72 \mathrm{~h}$ post-treatment, formulated curcumin caused cytotoxicity in Huh7, Mahlavu, and PLC5 cells with an IC 50 value of 38.1, 10.1, and $60.9 \mu \mathrm{M}$, respectively, while the $\mathrm{IC}_{50}$ values of conventional curcumin were $53.3,35.4$, and $82.5 \mu \mathrm{M}$, respectively (Figure 6A-C). Taken together, the results showed that both conventional and formulated curcumin inhibited the survival and proliferation of HCC cell lines in a dose-dependent manner. In addition, formulated curcumin was more effective than conventional curcumin.
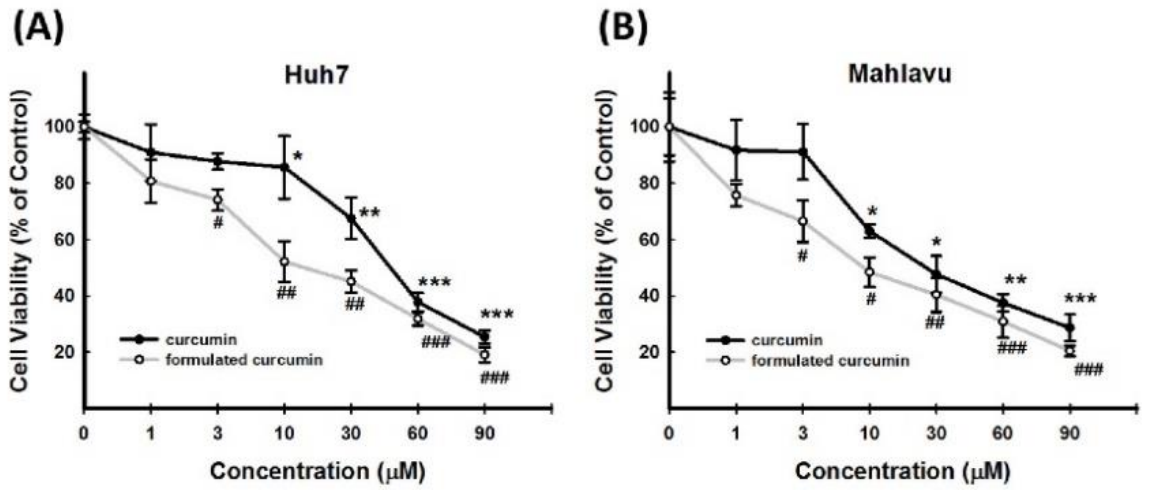

(C)

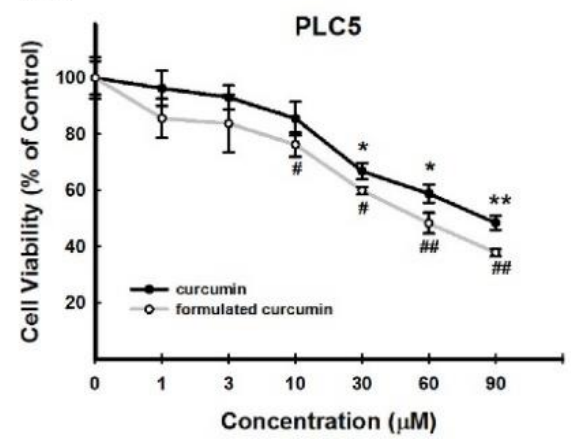

Figure 6. Cytotoxic effect of curcumin and formulated curcumin on other HCC cell lines (Huh7, Mahlavu, and PLC5). After separate treatment with 1, 3, 10, 30, 60, and $90 \mu \mathrm{M}$ of conventional and formulated curcumin for $72 \mathrm{~h}$, cell viability was determined by MTT assay and expressed as a percentage relative to the control group. Formulated curcumin was more effective than conventional curcumin on the basis of cell viability in the three cell lines tested. Formulated curcumin has higher cytotoxicity in (A) Huh7, (B) Mahlavu, and (C) PLC5 compared to conventional curcumin. ${ }^{\#} p<0.05$; ${ }^{\# \#} p<0.01$; ${ }^{\# \# \#} p<0.005$ compared to the control group (formulated curcumin). ${ }^{*} p<0.05 ;{ }^{* *} p<0.01 ;{ }^{* * *} p<0.005$ compared to the control group (conventional curcumin). MTT, 3-(4,5-cimethylthiazol-2-yl)-2,5-diphenyl tetrazolium bromide. 


\subsection{Effects of Curcumin on Apoptosis-Related Protein Expression}

MTT assay indicated that both conventional and formulated curcumin suppress cell viability. To determine whether cell viability inhibition is due to apoptosis, we examined the degree of apoptosis by PI and annexin V staining using flow cytometry. The results clearly demonstrated that $24 \mathrm{~h}$ post-treatment with 10-60 $\mu \mathrm{M}$ of conventional and formulated curcumin, the percentage of cells undergoing early apoptosis (annexin $\mathrm{V}^{+} / \mathrm{PI}^{-}$) and late apoptosis (annexin $\mathrm{V}^{+} / \mathrm{PI}^{+}$) increased, while the percentage of viable cells decreased (annexin $\mathrm{V}^{-} / \mathrm{PI}^{-}$) in a dose-dependent manner (Figure $7 \mathrm{~A}$ ). Comparison of effectiveness between conventional and formulated curcumin showed no significant statistical difference.

Caspase-3 activation is crucial for mitochondrial-dependent and mitochondrial-independent apoptotic pathways. Therefore, we examined the activity of caspase- 3 by observing its active form (cleaved form) by western blotting in Huh7 cells (Figure 7B). Both conventional and formulated curcumin increased caspase-3 activity in Huh7 cells in a dose-dependent manner (Figure 7B). Caspase-3 activation led to cleavage of several substrates, including PARP. PARP cleavage was also determined by western blotting (Figure 7B). Therefore, conventional and formulated curcumin separately induced apoptosis by activating caspase-3 (Figure 7B).

Many antineoplastic drugs induce apoptosis of cancer cells via mitochondrial apoptotic pathways [34-36]. A hallmark of apoptosis induction via these pathways is a rapid, early breakdown of the mitochondrial membrane potential. Therefore, in this study, we also analyzed the mitochondrial function integrity posttreatment with conventional and formulated curcumin. Both conventional and formulated curcumin significantly induced mitochondrial membrane potential breakdown $(\Delta \Psi \mathrm{m})$ in a concentration-dependent manner (Figure 7C), as determined by ELISA using the potential-sensitive dye JC-1.

Previous studies have shown that curcumin inhibits cancer cell proliferation via suppression of the ERK signaling pathway [37-39]. To investigate whether the ERK signaling pathway is involved in curcumin-induced apoptosis, ERK activation was evaluated by detecting ERK phosphorylation. Huh7 cells were exposed to 10-60 $\mu \mathrm{M}$ of conventional curcumin and formulated curcumin separately for $48 \mathrm{~h}$, and ERK activation was determined by western blotting. As shown in Figure 7D, both conventional and formulated curcumin-induced phosphor-ERK down-regulation but with little change in the total ERK protein in Huh7 cells.

Recent studies have suggested that a curcumin-induced mitotic spindle defect and cell cycle arrest in human cancer cells occur through Aurora kinase inhibition [40-42]. To determine whether conventional and formulated curcumin inhibit Huh7 cell proliferation via down-regulation of Aurora-A expression, Huh7 cells were incubated with 0-60 $\mu \mathrm{M}$ of conventional and formulated curcumin separately for $48 \mathrm{~h}$. We observed a significant decrease in the level of Aurora-A by western blotting (Figure 7D). These data suggested that the biological function of both conventional and formulated curcumin involves caspase-3 activation and ERK and Aurora-A down-regulation. 
(A)
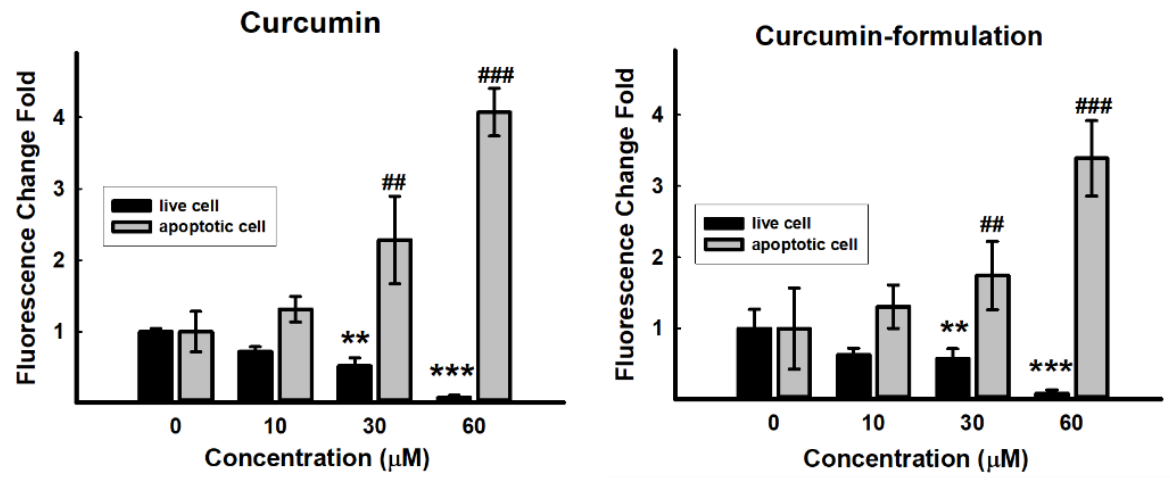

(B)

(C)
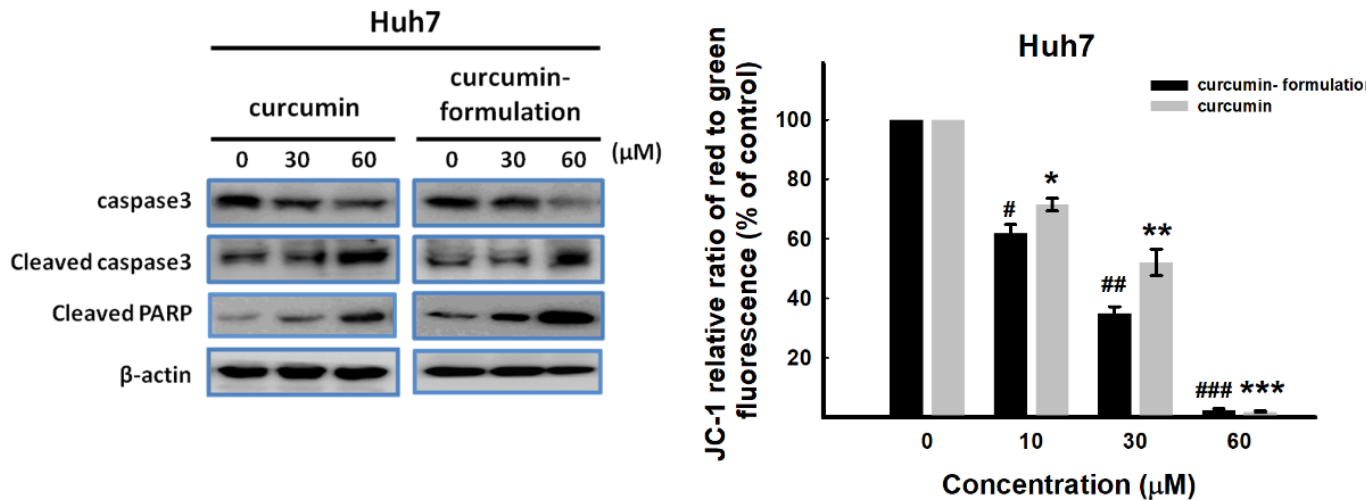

(D)

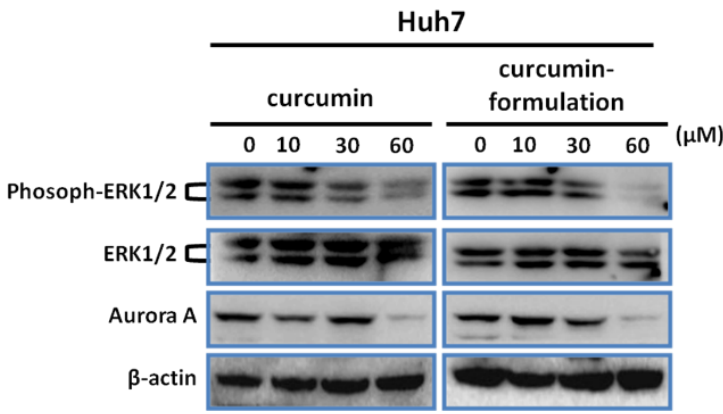

Figure 7. Both conventional and formulated curcumin caused apoptosis of Huh7 cells. (A) The cells were incubated and treated with conventional and formulated curcumin. After $24 \mathrm{~h}$, the cells were subjected to annexin V/PI staining and analyzed by flow cytometry. Quantitative analysis of PI- or annexin V-positive cells is shown $(n=3)$. ${ }^{* *} p<0.01$ and ${ }^{* * *} p<0.005$ compared to the live-cell group without treatment. ${ }^{\# \#} p<0.01$ and ${ }^{\# \#} p<0.005$ compared to the apoptotic cell group without treatment. (B) Huh7 cell lysates treated with conventional and formulated curcumin separately were subjected to immunoblot analysis. The expression levels of cleaved caspase-3, caspase-9, and PARP increased, demonstrating that the cells had undergone apoptosis. (C) The mitochondrial membrane potential $(\triangle \Psi \mathrm{m})$ in Huh7 cells was analyzed using the JC-1 mitochondrial membrane potential assay. $\Delta \Psi \mathrm{m}$ was lower in HCC cell lines treated with different concentrations $(10,30$, and $60 \mu \mathrm{M})$ of conventional or formulated curcumin compared to control HCC cell lines $(\mathrm{n}=3) .{ }^{*} p<0.05 ;{ }^{* *} p<0.01$; and ${ }^{* * *} p<0.005$ compared to the group without conventional curcumin treatment. ${ }^{\#} p<0.05$; ${ }^{\# \#} p<0.01$; and ${ }^{\# \# \#} p<0.005$ compared to the group without formulated curcumin treatment. (D) P-ERK and AURKA expression was down-regulated by conventional and formulated curcumin in a concentration-dependent manner, as shown by immunoblot analysis results with anti-ERK, anti-P-ERK, and anti-AURKA antibodies. PI, propidium iodide; PARP, poly (ADP-ribose) polymerase; ERK, extracellular regulated protein kinase; AURKA, aurora kinase A. 


\subsection{Effects of Combination of Curcumin and Sorafenib}

Sorafenib and curcumin both inhibited cell viability of two HCC cell lines (Huh7 and Hep3B) in a dose-dependent manner (Supplementary Figures S5 and S6). Therefore, we explored the potential effects of sorafenib in combination with conventional or formulated curcumin on Huh7, Mahlavu, and Hep3B cell proliferation. The cells were treated with various concentrations of sorafenib in combination with conventional or formulated curcumin for $48 \mathrm{~h}$ (Supplementary Figures S5A and S6). The results indicated that the combination of conventional or formulated curcumin with sorafenib has a stronger inhibitory effect on the population growth of HCC cell lines.

In this study, we demonstrated that both conventional and formulated curcumin inhibit Aurora kinase, preferentially suppress proliferation, and induce apoptosis of HCC cell lines. A previous study also indicated that curcumin induces apoptosis-associated autophagy [43,44]. Therefore, we investigated whether the combination of sorafenib and conventional or formulated curcumin can increase apoptosis of HCC cell lines. Cell cycle analysis revealed that adding conventional curcumin for $48 \mathrm{~h}$ leads to an apoptosis rate of 13.5\% (sub-G1 population), similar to the $10.9 \%$ rate induced by sorafenib. We further examined whether conventional curcumin induces apoptosis of Hep3B cells. We found that the levels of cleaved caspase-3 proteins increased in conventional curcumin-treated, sorafenib-treated, and combination-treated cells (Supplementary Figure S5C). There was no notable difference between the three groups. Conventional curcumin and its combination with sorafenib both significantly induced accumulation of LC3-II (Supplementary Figure S5D), a lipidated form of LC3 that is considered an autophagosomal marker in mammals. Similar results were found with formulated curcumin treatment (data not shown). These results suggested that the combination of conventional curcumin and formulated curcumin separately with sorafenib induces apoptosis-associated autophagy in HCC cell lines.

\section{Discussion}

In this study, we reported that (i) both conventional and formulated curcumin induce apoptosis of HCC cell lines and down-regulate Aurora-A and (ii) a combination of conventional or formulated curcumin with sorafenib has a stronger inhibitory effect on HCC cell viability, demonstrating a possible prevention and therapeutic application for formulated curcumin to be used as a food supplement and medical food.

HCC most often develops and progresses with a lot of oxidative stress and inflammation. Phytochemicals, such as dietary polyphenols, endowed with potent antioxidant and anti-inflammatory properties, provide a suitable alternative for alleviation of HCC. Previous studies have reported that systemic bioavailability of curcumin in humans is very poor $[45,46]$. Solid dispersion manufacturing of poorly soluble drugs by spray-drying is a practical commercialization strategy to improve solubility and dissolution rates because of the reasonable cost of required materials and ease of scale-up [47].

Several methods have been developed to solve issue of low oral bioavailability of curcumin. One method is the use of a natural enhancer, such as alkaloid piperine. When $20 \mathrm{mg}$ of piperine was given concomitantly with $2 \mathrm{~g}$ of curcumin, the serum curcumin increased by 20 times in humans and 1.56 times in rats. However, because piperine is a relatively selective CYP3A inhibitor [14], drug and food interactions with piperine are a concern. Some studies have used phospholipids as a delivery vehicle for curcumin. The oral bioavailability of curcumin-silica-coated flexible liposomes (curcumin-SLs) and curcumin-flexible liposomes (curcumin-FLs) was found to be 7.76- and 2.35-fold higher, respectively, compared to curcumin suspensions [20]. However, large-scale manufacturing will incur a substantial cost.

In the pharmaceutical industry, solid dispersion pellets are one of the drug delivery solutions for poorly soluble drugs. Solid dispersion pellets increase the solubility and release rate of a drug. For example, itraconazole is a triazole antifungal agent with low solubility. In some itraconazole solid dispersion pellets, the formulated itraconazole showed around 30- and 70-fold increase in the dissolution rate compared to pure drug [48]. Tanshinone IIA (TA), one of the liposoluble bioactive 
constituents extracted from the root of Salvia miltiorrhiza Bunge, has positive cardiovascular functions such as vasorelaxation and cardioprotective effects. The oral bioavailability of TA tSD pellets (a solid dispersion of a combination of PVP and poloxamer 188) in rabbit increased by 5.4 times compared to TA [49]. In this study, the oral bioavailability of formulated curcumin (solid dispersion pellets) increased significantly compared to conventional curcumin. Except for curcumin itself, all the materials used are inert and safe. In addition, because of the simple manufacturing process, solid dispersion pellets are also suitable for continuous and large-scale manufacturing, and the formulated curcumin can be used as a food supplement and medical food.

As mentioned in Section 3.1, 830-1000 $\mu \mathrm{m}$ is the size distribution of the pellets (formulated curcumin) determined by the sieving method. These pellets were formed by spraying ethanol solution of curcumin and PVP-K30 onto sugar spheres in a fluid-bed granulator machine. After re-dispersion in water, they were disintegrated to release free curcumin into the water as nanoparticles. The size of the curcumin particles (Z-average) measured using Zetasizer Nano ZS90 was determined to be $141.9 \pm 5.1 \mathrm{~nm}$, which could be filtered by a $0.45-\mu \mathrm{m}$ pore filter. The nano size of the curcumin particles made it possible for them to be dissolved quickly in the dissolution medium. This was compatible with the data of the dissolution test.

In addition, using $1 \%$ SDS solution as the media for the dissolution test is mentioned in the US Pharmacopeia for curcuminoid tablets or curcuminoid capsules. Therefore, we used SDS in the medium to evaluate how well our newly formulated curcumin was improved in its dissolution by comparison with conventional curcumin. The results showed that dissolution of conventional curcumin in $1 \%$ SDS solution was only about $20 \%$ after 60 minutes, whereas that of the formulated curcumin was more than $85 \%$ after 10 minutes.

Supplementary Table S1 summarizes several studies that have reported techniques for enhancing curcumin oral bioavailability. While the formulated curcumin increases bioavailability over 800 -fold, only approximately $5-100$-fold increases have been achieved by other formulations. To clarify this difference, we investigated several pharmacokinetic parameters of conventional curcumin from these studies (supplementary Table S2) ([50-52]). In our study, administration of $500 \mathrm{mg} / \mathrm{kg}$ of curcumin resulted in a very low amount of curcumin in rat plasma: $\mathrm{AUC}_{0-\mathrm{t}}(\mathrm{h} \times \mathrm{ng} / \mathrm{mL})$ was 1.1 , whereas in other studies the $\mathrm{AUC}_{0-\mathrm{t}}(\mathrm{h} \times \mathrm{ng} / \mathrm{mL})$ were $8.76,80$, and 60 after doses of 50,340 , and $500 \mathrm{mg} / \mathrm{kg}$, respectively, were administered. If we used these $\mathrm{AUC}_{0-\mathrm{t}}(\mathrm{h} \times \mathrm{ng} / \mathrm{mL})$ from un-formulated curcumin to calculate the AUC for the formulated curcumin, an approximately 8-16-fold increase in bioavailability was obtained. In short, this study showed that oral administration of a novel solid dispersion of curcumin significantly increased its oral bioavailability compared with that of conventional curcumin. Although the $C_{\max }$ of the formulated curcumin is far below the effective concentrations of our cell culture experiments, administration of conventional curcumin $(200 \mathrm{mg} / \mathrm{kg})$ for days or weeks has been reported to exhibit significant biological activity against both chemically induced and xenograft hepatocarcinogenesis [53]. Because the formulated curcumin (single administration of $60 \mathrm{mg} / \mathrm{kg}$ ) significantly increased the oral bioavailability compared with conventional curcumin (single administration of $500 \mathrm{mg} / \mathrm{kg}$ ), repeating administration of the formulated curcumin at a higher dosage for a longer period of time can be expected to achieve a much higher $C_{\max }$, and especially AUC, to display the biological effect of curcumin observed in vitro. It is noteworthy that the formulated curcumin, as expected, retains similar characteristics to conventional curcumin at the cellular level.

It is well known that the low oral bioavailability of curcumin is due to its poor solubility, poor intestinal permeability and extensive metabolism. In another study [52], authors have used phospholipid to formulate liposome of curcumin in order to enhance intestinal absorption of curcumin. In the fasted rat model (rats were fasted overnight to avoid interference by food), they proved that the AUC for liposome of curcumin increased about 5.5-fold compared with that for the conventional curcumin after administration of $340 \mathrm{mg} / \mathrm{kg}$ dose; the AUC $26.7 \mu \mathrm{g} \times \mathrm{min} / \mathrm{mL}$ is equivalent to $445 \mathrm{~h}$ $\times \mathrm{ng} / \mathrm{mL}$. In our study, rats had free access to food and water. After administrating $60 \mathrm{mg} / \mathrm{kg}$ of the formulated curcumin, the AUC recorded was approximately $111 \mathrm{~h} \times \mathrm{ng} / \mathrm{mL}$. In addition, AUC/dose 
calculated in our study was higher than that in the previous study. Although we enhanced solubility of curcumin, we suggest that after administration of our formulation, curcumin was quickly released as nano particles then dissolved in gastric fluid or tiny oil droplet in food. Therefore, a part of curcumin was absorbed as free form and the rest was absorbed by pathway of oil absorption supported by bile salts. This was one of the advantages of the formulated curcumin which can be prepared easily and scaled up in industry. In future, we will conduct more experiments to verify this conclusion.

Both conventional and formulated curcumin were effective in decreasing proliferation and viability of HCC cell lines in a dose-dependent manner and induced apoptosis of HCC cell lines via mitochondria dysfunction in vitro. In the cell culture study, both forms of curcumin were dissolved completely before experiments, thus the benefits of formulated curcumin with improved solubility and dissolution rates could not be displayed. The in vitro study was carried out mainly to determine if the formulated curcumin retained similar characteristics of conventional curcumin at the cellular level. Mitochondrial hyperpolarization is a prerequisite for curcumin-induced apoptosis, and mitochondrial DNA (mtDNA) damage might be a probable mechanism for curcumin-induced apoptosis of HepG2 cells and might serve as the initial event triggering a chain of events leading to apoptosis [12]. Aurora kinases, such as Aurora-A, Aurora-B, and Aurora-C, comprise a family of centrosome-associated serine/threonine kinases that are overexpressed in various cancers and are potentially correlated with chemoresistance [54-56]. Curcumin administration [57] or Aurora-A inhibition by short interfering RNA (siRNA) [58] induces apoptosis. Curcumin has also been shown to down-regulate Notch1, the janus kinase (JAK)/signal transducer and activator of transcription (STAT) pathway, and multidrug resistance protein 1 (MDR1) expression and to inhibit histone deacetylase 1 (HDAC1) activity [12,13,42,59,60]. Sorafenib is the only chemotherapeutic drug that has been shown to be effective in prolonging the survival of HCC patients. However, the low rate of tolerance to sorafenib among HCC patients limits its use [31,32]. Recent preclinical studies have reported that combining sorafenib with other chemotherapeutic agents exerts synergistic effects [61,62], which could provide a promising strategy for the treatment of advanced HCC. In this study, conventional or formulated curcumin in combination with sorafenib inhibited the proliferation of HCC cell lines and exhibited a stronger inhibitory effect on HCC cell lines. Taken together, the formulated curcumin appeared to have properties similar to conventional curcumin, raising the possibility that our formulated curcumin could enhance cytotoxicity against HCC.

In addition, our bioinformatics screening platform effectively identified the molecular mechanisms of a phytochemical via gene expression profiles. C-Map can be queried to identify specific gene signatures from small molecules, including FDA-approved drugs. CLUE is similar to C-Map but considerably larger, with $>1.1$ million L1000 profiles; therefore, similarity scores for compounds in CLUE can be obtained to identify their molecular actions. Similar results for conventional and formulated curcumin suggested that only solubility and oral bioavailability have been altered in formulated curcumin. Curcumin is known to exert strong anti-inflammatory effects by interrupting NF-KB signaling at multiple levels. Based on CLUE analysis, formulated curcumin can be predicted to have a similar action as NF- $\mathrm{KB}$ pathway inhibitors. Furthermore, analysis via CPDB suggests that curcumin can be linked to TNF related weak inducer of apoptosis as well as TNF mediated NF- $\kappa B$ pathway. Therefore, our screening platform not only confirms that the formulated curcumin has similar mechanism with unformulated curcumin, but it also predicts the novel mechanism of formulated curcumin, such as suppression of HMGB1 mediated inflammation by THBD (label in red in Supplementary Figure S2).

In conclusion, our curcumin was formulated in pellet form, which not only improved its oral bioavailability but also provided high flexibility of use. For example, it would be easy to adjust the dosage and combine the pellets with other ingredients. In addition, as a functional food and alternative medicine, it would be suitable for those who cannot swallow tablets or capsules. 
Supplementary Materials: The following are available online: http://www.mdpi.com/2072-6643/11/12/2982/s1. Figure S1. The dissolution rates of conventional and formulated curcumin in $1 \%$ sodium dodecyl sulfate medium, Figure S2. Prediction of highly correlated pathways, Figure S3. The output data of compounds (CP, score $\geq 90)$ was analyzed via CLUE, and detected their similarity among these gene expression profiles, Figure S4. Curcumin and the formulated curcumin affect the cell viability of Huh7 cells, Figure S5. Inhibitory effect of the combination of sorafenib and conventional or formulated curcumin on HCC cell lines, Figure S6. Effect of sorafenib with or without curcumin/formulated curcumin on Mahlavu and Hep3B cell viability, Table S1. Comparison between our study and previous studies on the improvement of solubility/oral bioavailability of curcumin formulation, Table S2. Comparison of pharmacokinetic parameters of curcumin in rat plasma following oral administration.

Author Contributions: S.-C.L. and W.-H.H. initiated the studies, performed and analyzed the majority of the experiments. C.-L.S., T.-H.T., and C.-Y.F.H. conceived and designed the experiments. K.-T.L., Z.-Y.H., K.-L.C., C.-L.T., and A.-H.D. performed the experiments and analyzed data. All authors contributed his/her efforts to write the manuscript.

Funding: This work was supported by the grants from the Yang-Ming University collaboration project (YM106C024). This work was also supported by grants from the National Science Council, Taiwan (NSC 101-2313-B-003-002-MY3) and the Ministry of Science and Technology, Taiwan (MOST 106-2320-B-003-006-MY3, MOST 107-2320-B-003-002-MY2, and MOST 107-2320-B-010-040-MY3).

Acknowledgments: We thank the Everest Pharm. Industrial Co., LTD., Chiayi, Taiwan, for the experiment drug supply and Rosetta Pharmamate Co., Ltd. for helping with animal pharmacokinetic study.

Conflicts of Interest: No potential conflicts of interest were disclosed. Competing financial interests statement: The authors declare that there is no conflict of interest.

\section{Abbreviations}

\section{Full Name}

area under curve

aurora kinase A

bioavailability

dimethyl sulfoxide

Dulbecco's modified Eagle's medium

enhanced chemiluminescence

extracellular regulated protein kinases

hepatocellular carcinoma

high performance liquid chromatography

histone deacetylase 1

janus kinase

limit of quantification

limits of detection

multidrug resistance protein 1

platelet-derived growth factor receptor beta

poly (ADP-ribose) polymerase

polydispersity index

polyvinylidene difluoride

propidium iodide

signal transducer and activator of transcription

sodium dodecyl sulfate

Tanshinone IIA

The Food and Drug Administration

vascular endothelial growth factor receptor

Abbreviations
AUC
AURKA
BA
DMSO
DMEM
ECL
ERK
HCC
HPLC
HDAC1
JAK
LOQ
LOD
MDR1
PDGFR- $\beta$
PARP
PDI
PVDF
PI
STAT
SDS
TA
FDA
VEGFR

\section{References}

1. Sheikh, B.Y.; Sarker, M.M.R.; Kamarudin, M.N.A.; Ismail, A. Prophetic medicine as potential functional food elements in the intervention of cancer: A review. Biomed. Pharm. 2017, 95, 614-648. [CrossRef] [PubMed]

2. Shahidi, F. Nutraceuticals, Functional Foods and Dietary Supplements in Health and Disease. J. Food Drug Anal. 2012, 20, 226-230. 
3. Sharma, R.A.; Gescher, A.J.; Steward, W.P. Curcumin: The story so far. Eur. J. Cancer. 2005, 41, $1955-1968$. [CrossRef] [PubMed]

4. Oyama, Y.; Masuda, T.; Nakata, M.; Chikahisa, L.; Yamazaki, Y.; Miura, K.; Okagawa, M. Protective actions of 5'-n-alkylated curcumins on living cells suffering from oxidative stress. Eur. J. Pharmacol. 1998, 360, 65-71. [CrossRef]

5. Maheshwari, R.K.; Singh, A.K.; Gaddipati, J.; Srimal, R.C. Multiple biological activities of curcumin: A short review. Life Sci. 2006, 78, 2081-2087. [CrossRef]

6. Ono, K.; Hasegawa, K.; Naiki, H.; Yamada, M. Curcumin has potent anti-amyloidogenic effects for Alzheimer's beta-amyloid fibrils in vitro. J. Neurosci. Res. 2004, 75, 742-750. [CrossRef]

7. Pal, S.; Choudhuri, T.; Chattopadhyay, S.; Bhattacharya, A.; Datta, G.K.; Das, T.; Sa, G. Mechanisms of curcumin-induced apoptosis of Ehrlich's ascites carcinoma cells. Biochem. Biophys. Res. Commun. 2001, 288, 658-665. [CrossRef]

8. Pal, S.; Bhattacharyya, S.; Choudhuri, T.; Datta, G.K.; Das, T.; Sa, G. Amelioration of immune cell number depletion and potentiation of depressed detoxification system of tumor-bearing mice by curcumin. Cancer Detect. Prev. 2005, 29, 470-478. [CrossRef]

9. Nautiyal, J.; Banerjee, S.; Kanwar, S.S.; Yu, Y.; Patel, B.B.; Sarkar, F.H.; Majumdar, A.P. Curcumin enhances dasatinib-induced inhibition of growth and transformation of colon cancer cells. Int. J. Cancer 2011, 128, 951-961. [CrossRef]

10. Duvoix, A.; Blasius, R.; Delhalle, S.; Schnekenburger, M.; Morceau, F.; Henry, E.; Dicato, M.; Diederich, M. Chemopreventive and therapeutic effects of curcumin. Cancer Lett. 2005, 223, 181-190. [CrossRef]

11. Kunwar, A.; Barik, A.; Mishra, B.; Rathinasamy, K.; Pandey, R.; Priyadarsini, K.I. Quantitative cellular uptake, localization and cytotoxicity of curcumin in normal and tumor cells. Biochim. Biophys. Acta 2008, 1780, 673-679. [CrossRef]

12. Cao, J.; Liu, Y.; Jia, L.; Zhou, H.M.; Kong, Y.; Yang, G.; Jiang, L.P.; Li, Q.J.; Zhong, L.F. Curcumin induces apoptosis through mitochondrial hyperpolarization and mtDNA damage in human hepatoma G2 cells. Free Radic. Biol. Med. 2007, 43, 968-975. [CrossRef] [PubMed]

13. Wang, W.Z.; Zhang, B.Y.; Yuan, J.; Mao, J.W.; Mei, W.J. [Effect of curcumin on JAK-STAT signaling pathway in hepatoma cell lines]. Yao Xue Xue Bao Acta Pharm. Sin. 2009, 44, 1434-1439.

14. Deguchi, A. Curcumin targets in inflammation and cancer. Endocr. Metab. Immune Disord. Drug Targets 2015, 15, 88-96. [CrossRef] [PubMed]

15. Lin, L.I.; Ke, Y.F.; Ko, Y.C.; Lin, J.K. Curcumin inhibits SK-Hep-1 hepatocellular carcinoma cell invasion in vitro and suppresses matrix metalloproteinase-9 secretion. Oncology 1998, 55, 349-353. [CrossRef] [PubMed]

16. Magini, A.; Polchi, A.; Di Meo, D.; Mariucci, G.; Sagini, K.; De Marco, F.; Cassano, T.; Giovagnoli, S.; Dolcetta, D.; Emiliani, C. TFEB activation restores migration ability to Tsc1-deficient adult neural stem/progenitor cells. Hum. Mol. Genet. 2017, 26, 3303-3312. [CrossRef]

17. Pan, M.H.; Huang, T.M.; Lin, J.K. Biotransformation of curcumin through reduction and glucuronidation in mice. Drug Metab. Dispos. Biol. Fate Chem. 1999, 27, 486-494.

18. Vareed, S.K.; Kakarala, M.; Ruffin, M.T.; Crowell, J.A.; Normolle, D.P.; Djuric, Z.; Brenner, D.E. Pharmacokinetics of curcumin conjugate metabolites in healthy human subjects. Cancer Epidemiol. Biomark. Prev. 2008, 17, 1411-1417. [CrossRef]

19. Wahlstrom, B.; Blennow, G. A study on the fate of curcumin in the rat. Acta Pharmacol. Toxicol. 1978, 43, 86-92. [CrossRef]

20. Siviero, A.; Gallo, E.; Maggini, V.; Gori, L.; Mugelli, A.; Firenzuoli, F.; Vannacci, A. Curcumin, a golden spice with a low bioavailability. J. Herb. Med. 2015, 5, 57-70. [CrossRef]

21. Song, J.X.; Sun, Y.R.; Peluso, I.; Zeng, Y.; Yu, X.; Lu, J.H.; Xu, Z.; Wang, M.Z.; Liu, L.F.; Huang, Y.Y.; et al. A novel curcumin analog binds to and activates TFEB in vitro and in vivo independent of MTOR inhibition. Autophagy 2016, 12, 1372-1389. [CrossRef] [PubMed]

22. Magini, A.; Polchi, A.; Di Meo, D.; Buratta, S.; Chiaradia, E.; Germani, R.; Emiliani, C.; Tancini, B. Curcumin analogue $\mathrm{C} 1$ promotes hex and gal recruitment to the plasma membrane via mTORC1-independent TFEB activation. Int. J. Mol. Sci. 2019, 20, 1363. [CrossRef] [PubMed]

23. Vikash, K.; Kumar, M.S.; Amit, L.; Singh, R. Multiple unit dosage form-pellet and pelletization techniques: An overview. Int. J. Res. Ayurveda Pharm. 2011, 2, 121-125.

24. Dhirendra, K.; Lewis, S.; Udupa, N.; Atin, K. Solid dispersions: A review. Pak. J. Pharm. Sci. 2009, 22, $234-246$. 
25. Lamb, J.; Crawford, E.D.; Peck, D.; Modell, J.W.; Blat, I.C.; Wrobel, M.J.; Lerner, J.; Brunet, J.P.; Subramanian, A.; Ross, K.N.; et al. The Connectivity Map: Using gene-expression signatures to connect small molecules, genes, and disease. Science 2006, 313, 1929-1935. [CrossRef]

26. Subramanian, A.; Narayan, R.; Corsello, S.M.; Peck, D.D.; Natoli, T.E.; Lu, X.; Gould, J.; Davis, J.F.; Tubelli, A.A.; Asiedu, J.K.; et al. A Next Generation Connectivity Map: L1000 Platform and the First 1,000,000 Profiles. Cell 2017, 171, 1437-1452. [CrossRef]

27. Guo, J.; Li, L.; Guo, B.; Liu, D.; Shi, J.; Wu, C.; Chen, J.; Zhang, X.; Wu, J. Mechanisms of resistance to chemotherapy and radiotherapy in hepatocellular carcinoma. Transl. Cancer Res. 2018, 7, 765-781. [CrossRef]

28. Lohitesh, K.; Chowdhury, R.; Mukherjee, S. Resistance a major hindrance to chemotherapy in hepatocellular carcinoma: An insight. Cancer Cell Int. 2018, 18, 44. [CrossRef]

29. Llovet, J.M.; Ricci, S.; Mazzaferro, V.; Hilgard, P.; Gane, E.; Blanc, J.F.; de Oliveira, A.C.; Santoro, A.; Raoul, J.L.; Forner, A.; et al. Sorafenib in advanced hepatocellular carcinoma. N. Eng. J. Med. 2008, 359, 378-390. [CrossRef]

30. Reig, M.; Bruix, J. Sorafenib for hepatocellular carcinoma: Global validation. Gastroenterology 2009, 137, 1171-1173. [CrossRef]

31. Welker, M.W.; Lubomierski, N.; Gog, C.; Herrmann, E.; Engels, K.; Vogl, T.J.; Bechstein, W.O.; Zeuzem, S.; Trojan, J. Efficacy and safety of sorafenib in advanced hepatocellular carcinoma under daily practice conditions. J. Chemother. 2010, 22, 205-211. [CrossRef] [PubMed]

32. Morimoto, M.; Numata, K.; Kondo, M.; Hidaka, H.; Takada, J.; Shibuya, A.; Kobayashi, S.; Ohkawa, S.; Okuse, C.; Morita, S.; et al. Higher discontinuation and lower survival rates are likely in elderly Japanese patients with advanced hepatocellular carcinoma receiving sorafenib. Hepatol. Res. 2011, 41, $296-302$. [CrossRef] [PubMed]

33. Liao, S.C.; Hsu, H.W.; Chuang, K.L.; Huang, Z.Y.; Lin, K.T.; Hsu, W.H.; Chang, K.H.; Huang, C.F.; Su, C.L. Using the Pleiotropic Characteristics of Curcumin to Validate the Potential Application of a Novel Gene Expression Screening Platform. Nutrients 2019, 11, 1397. [CrossRef]

34. Jendrossek, V.; Handrick, R.; Belka, C. Celecoxib activates a novel mitochondrial apoptosis signaling pathway. FASEB J. 2003, 17, 1547-1549. [CrossRef] [PubMed]

35. Wieder, T.; Essmann, F.; Prokop, A.; Schmelz, K.; Schulze-Osthoff, K.; Beyaert, R.; Dorken, B.; Daniel, P.T. Activation of caspase- 8 in drug-induced apoptosis of B-lymphoid cells is independent of CD95/Fas receptor-ligand interaction and occurs downstream of caspase-3. Blood 2001, 97, 1378-1387. [CrossRef]

36. Engels, I.H.; Stepczynska, A.; Stroh, C.; Lauber, K.; Berg, C.; Schwenzer, R.; Wajant, H.; Janicke, R.U.; Porter, A.G.; Belka, C.; et al. Caspase-8/FLICE functions as an executioner caspase in anticancer drug-induced apoptosis. Oncogene 2000, 19, 4563-4573. [CrossRef]

37. Shin, H.K.; Kim, J.; Lee, E.J.; Kim, S.H. Inhibitory effect of curcumin on motility of human oral squamous carcinoma YD-10B cells via suppression of ERK and NF-kappaB activations. Phytother. Res. 2010, 24, 577-582. [CrossRef]

38. Xie, Y.Q.; Wu, X.B.; Tang, S.Q. Curcumin treatment alters ERK-1/2 signaling in vitro and inhibits nasopharyngeal carcinoma proliferation in mouse xenografts. Int. J. Clin. Exp. Med. 2014, 7, 108-114.

39. Guo, Y.; Shan, Q.; Gong, Y.; Lin, J.; Shi, F.; Shi, R.; Yang, X. Curcumin induces apoptosis via simultaneously targeting AKT/mTOR and RAF/MEK/ERK survival signaling pathways in human leukemia THP-1 cells. Pharmazie 2014, 69, 229-233.

40. Wolanin, K.; Magalska, A.; Mosieniak, G.; Klinger, R.; McKenna, S.; Vejda, S.; Sikora, E.; Piwocka, K. Curcumin affects components of the chromosomal passenger complex and induces mitotic catastrophe in apoptosis-resistant Bcr-Abl-expressing cells. Mol. Cancer Res. 2006, 4, 457-469. [CrossRef]

41. Liu, H.S.; Ke, C.S.; Cheng, H.C.; Huang, C.Y.; Su, C.L. Curcumin-induced mitotic spindle defect and cell cycle arrest in human bladder cancer cells occurs partly through inhibition of aurora A. Mol. Pharmacol. 2011, 80, 638-646. [CrossRef] [PubMed]

42. Ke, C.S.; Liu, H.S.; Yen, C.H.; Huang, G.C.; Cheng, H.C.; Huang, C.Y.; Su, C.L. Curcumin-induced Aurora-A suppression not only causes mitotic defect and cell cycle arrest but also alters chemosensitivity to anticancer drugs. J. Nutr. Biochem. 2014, 25, 526-539. [CrossRef] [PubMed]

43. Li, B.; Takeda, T.; Tsuiji, K.; Wong, T.F.; Tadakawa, M.; Kondo, A.; Nagase, S.; Yaegashi, N. Curcumin induces cross-regulation between autophagy and apoptosis in uterine leiomyosarcoma cells. Int. J. Gynecol. Cancer 2013, 23, 803-808. [CrossRef] [PubMed] 
44. Zhou, T.; Ye, L.; Bai, Y.; Sun, A.; Cox, B.; Liu, D.; Li, Y.; Liotta, D.; Snyder, J.P.; Fu, H.; et al. Autophagy and apoptosis in hepatocellular carcinoma induced by EF25-(GSH)2: A novel curcumin analog. PLoS ONE 2014, 9. [CrossRef] [PubMed]

45. Lao, C.D.; Ruffin, M.T.T.; Normolle, D.; Heath, D.D.; Murray, S.I.; Bailey, J.M.; Boggs, M.E.; Crowell, J.; Rock, C.L.; Brenner, D.E. Dose escalation of a curcuminoid formulation. BMC Complementary Altern. Med. 2006, 6, 10. [CrossRef]

46. Sharma, R.A.; Euden, S.A.; Platton, S.L.; Cooke, D.N.; Shafayat, A.; Hewitt, H.R.; Marczylo, T.H.; Morgan, B.; Hemingway, D.; Plummer, S.M.; et al. Phase I clinical trial of oral curcumin: Biomarkers of systemic activity and compliance. Clin. Cancer Res. 2004, 10, 6847-6854. [CrossRef]

47. Vasconcelos, T.; Sarmento, B.; Costa, P. Solid dispersions as strategy to improve oral bioavailability of poor water soluble drugs. Drug Discov. Today 2007, 12, 1068-1075. [CrossRef]

48. Ye, G.; Wang, S.; Heng, P.W.; Chen, L.; Wang, C. Development and optimization of solid dispersion containing pellets of itraconazole prepared by high shear pelletization. Int. J. Pharm. 2007, 337, 80-87. [CrossRef]

49. Li, J.; Liu, P.; Liu, J.P.; Zhang, W.L.; Yang, J.K.; Fan, Y.Q. Novel Tanshinone II A ternary solid dispersion pellets prepared by a single-step technique: In vitro and in vivo evaluation. Eur. J. Pharm. Biopharm. 2012, 80, 426-432. [CrossRef]

50. Yang, K.Y.; Lin, L.C.; Tseng, T.Y.; Wang, S.C.; Tsai, T.H. Oral bioavailability of curcumin in rat and the herbal analysis from Curcuma longa by LC-MS/MS. J. Chromatogr. B 2007, 853, 183-189. [CrossRef]

51. Khalil, N.M.; do Nascimento, T.C.; Casa, D.M.; Dalmolin, L.F.; de Mattos, A.C.; Hoss, I.; Romano, M.A.; Mainardes, R.M. Pharmacokinetics of curcumin-loaded PLGA and PLGA-PEG blend nanoparticles after oral administration in rats. Colloids Surf. B Biointerfaces 2013, 101, 353-360. [CrossRef] [PubMed]

52. Marczylo, T.H.; Verschoyle, R.D.; Cooke, D.N.; Morazzoni, P.; Steward, W.P.; Gescher, A.J. Comparison of systemic availability of curcumin with that of curcumin formulated with phosphatidylcholine. Cancer Chemother. Pharmacol. 2007, 60, 171-177. [CrossRef] [PubMed]

53. Darvesh, A.S.; Aggarwal, B.B.; Bishayee, A. Curcumin and liver cancer: A review. Curr. Pharm. Biotechnol. 2012, 13, 218-228. [CrossRef] [PubMed]

54. Lin, Z.Z.; Jeng, Y.M.; Hu, F.C.; Pan, H.W.; Tsao, H.W.; Lai, P.L.; Lee, P.H.; Cheng, A.L.; Hsu, H.C. Significance of Aurora B overexpression in hepatocellular carcinoma. Aurora B Overexpression in HCC. BMC Cancer 2010, 10, 461. [CrossRef]

55. Carmena, M.; Earnshaw, W.C. The cellular geography of aurora kinases. Nat. Rev. Mol. Cell Biol. 2003, 4, 842-854. [CrossRef]

56. Jeng, Y.M.; Peng, S.Y.; Lin, C.Y.; Hsu, H.C. Overexpression and amplification of Aurora-A in hepatocellular carcinoma. Clin. Cancer Res. 2004, 10, 2065-2071. [CrossRef]

57. Woo, J.H.; Kim, Y.H.; Choi, Y.J.; Kim, D.G.; Lee, K.S.; Bae, J.H.; Min, D.S.; Chang, J.S.; Jeong, Y.J.; Lee, Y.H.; et al. Molecular mechanisms of curcumin-induced cytotoxicity: Induction of apoptosis through generation of reactive oxygen species, down-regulation of Bcl-XL and IAP, the release of cytochrome $\mathrm{c}$ and inhibition of Akt. Carcinogenesis 2003, 24, 1199-1208. [CrossRef]

58. Du, J.; Hannon, G.J. Suppression of p160ROCK bypasses cell cycle arrest after Aurora-A/STK15 depletion. Proc. Natl. Acad. Sci. USA 2004, 101, 8975-8980. [CrossRef]

59. Ning, L.; Wentworth, L.; Chen, H.; Weber, S.M. Down-regulation of Notch1 signaling inhibits tumor growth in human hepatocellular carcinoma. Am. J. Transl. Res. 2009, 1, 358-366.

60. Wang, W.; Zhang, B.; Chen, H.; Zhang, L. Anticancer activities of curcumin on human hepatocarcinoma cell line Sk-hep-1. Zhongguo Zhong Yao Za Zhi 2010, 35, 485-488.

61. Singh, S.; Singh, P.P.; Roberts, L.R.; Sanchez, W. Chemopreventive strategies in hepatocellular carcinoma. Nat. Rev. Gastroenterol. Hepatol. 2014, 11, 45-54. [CrossRef] [PubMed]

62. Abou-Alfa, G.K.; Johnson, P.; Knox, J.J.; Capanu, M.; Davidenko, I.; Lacava, J.; Leung, T.; Gansukh, B.; Saltz, L.B. Doxorubicin plus sorafenib vs doxorubicin alone in patients with advanced hepatocellular carcinoma: A randomized trial. JAMA 2010, 304, 2154-2160. [CrossRef] [PubMed]

(C) 2019 by the authors. Licensee MDPI, Basel, Switzerland. This article is an open access article distributed under the terms and conditions of the Creative Commons Attribution (CC BY) license (http://creativecommons.org/licenses/by/4.0/). 